CALORIMETRIC BEHAVIOR OF METHACRYLIC POLYMERS ".

by

Douglas Osborne Hubbell

Thesis submitted to the Graduate Faculty of the Virginia Polytechnic Institute in candidacy for the degree of MASTER OF SCIENCE in

CHEMICAL ENGINEERING 
LIST OF TABLES $\ldots \ldots \ldots \ldots \ldots \ldots \ldots \ldots \ldots \ldots \ldots \ldots$

IIST OF FIGURES.................. vi

I. INTRODUCTION....................... I

II. LITERATURE REVIEW................... 2

The Acrylic Polymers................ 2

Properties of Polymethyl Methacrylate.. 2

Uses of Polymethyl Methacrylate...... 3

Higher Methacrylates and Polyacrylates........................ 3

Selected Acrylic Polymers.......... 4

Calorimetry and Specific heat.......... 4

The Drop Calorimeter Assembly.......6 6

Aluminum Oxide as a Standard......... 8

The Calorimeter Section.......... 9

Precision of Measurements.......... 9

Specific Heat Estimations.......... 10

Available Specific Heats.......... 12

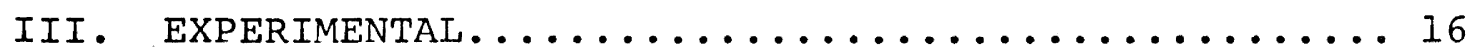

Plan of Experimentation............. 16

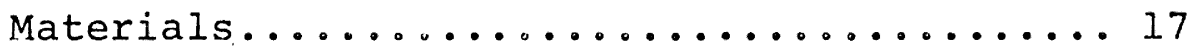

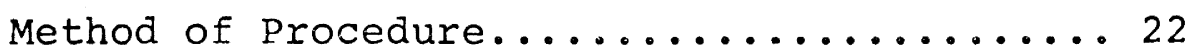

Polymerizations.................. 22

Calibrations..................... 23

Calorimetric Determinations........ 23 
Data and Results................. 26

Calorimeter Data................ 26

Specific Heats.............. 26

Estimations and Correlations....... 26

Sample Calculations............... 42

Sample Enthalpies............ 42

Specific Heats................ 44

Sakiadis and Coates' Method......... 45

IV. DISCUSSION..................... 47

Discussion of Literature............ 47

Calorimeter................. 47

Specific Heat Estimations......... 47

Discussion of Procedures............. 49

Polymerizations................ 49

Calorimetric Determinations........ 49

Discussion of Results............. 50

The Data..................... 50

Specific Heats............... 51

Literature Agreement............ 51

Empirical Correlation of Specific Heats.................. 52

Application of Present Theories..... 52

Modified Estimation Techniques...... 53 


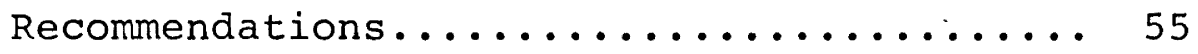

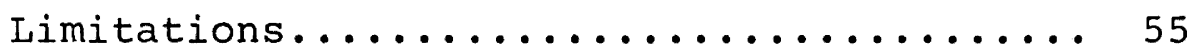

V. CONCLUSIONS.......................... 56

VI. SUMMARY........................... 57

VII. BIBLIOGRAPHY ...................... 58

VIII. ACKNOWLEDGEMENTS ...................... 61

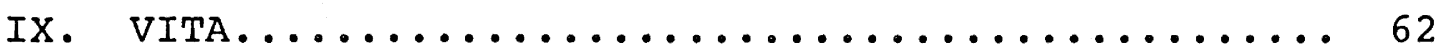




\section{LIST OF TABHES}

Page

Table I. Specific Heat and Enthalpy of Polymethyl Methacrylate at Low

Temperatures................. 15

Table II. System Constants............... 27

Table III. Calorimeter Data............... 28

Table IV. Smoothed Enthalpies of Selected Polymers.. 30

Table V. Specific Heats of Selected Polymers...... 31

Table VI. Correlation of Specific Heats of Linear Methacrylic Polymers............ 34

Table VII. Atomic Group Heat Capacity Contributions

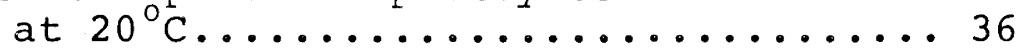

Table VIII. Specific Heat Estimations at Normal Temperatures.......................... 37

Table IX. Modified Correction Factors for Sakiadis and Coates' Method for Polymers..... 38

Table $x$. Sakiadis and Coates' Specific Heat Estimations.................41 


\section{LIST OF FIGURES}

Page

Figure 1. Selected Polymers.................. 5

Figure 2. Specific Heat of Polymethyl Methacrylate at High Temperatures.............. 13

Figure 3. Drop Calorimeter................... 24

Figure 4. Enthalpies of Selected Polymers.......... 29

Figure 5. Specific Heats of Polymethyl Methacrylate and Polyethyl Acrylate................ 32

Figure 6. Specific Heats of Methacrylics.......... 33

Figure 7. Correlation of Specific Heats of Linear Methacrylic Polymers............. 35

Figure 8. Heat Capacity Correction Factors as Functions of Temperature............ 39

Figure 9. Heat Capacity Correction Factor as a Function of Mer Weight............. 40 


\section{INTRODUCTION}

The production of polymeric materials has recently become one of the largest and fastest growing industries in the world today. Plastics are finding new applications daily, having already invaded almost every other major industry.

Polymer processing today is accomplished largely by trial and error experimentation and knowledge of previous experience. Many plastics are processed as viscous, non-Newtonian fluids for which little engineering or thermodynamic data are available. There are no satisfactory theoretical methods for estimating thermodynamic properties of polymers. The knowledge of these properties is essential for processing and proper evaluation of end uses.

The object of this work was to determine the enthalpies and specific heats of polyethyl acrylate, polymethyl methacrylate, polyallyl methacrylate, polydimethylaminoethyl methacrylate, and polycyclohexyl methacrylate from 100 to $300^{\circ} \mathrm{C}$ and to develop a method of estimating these thermodynamic properties. 


\section{LITFRATURE REVIEW}

The literature review for this study is divided into a discussion of the acrylic polymers, their properties and uses, and a survey of the calorimetry of these materials.

\section{The Acrylic Polymers}

Polymethyl methacrylate is the most important of the acrylic polymers. Billmeyer ${ }^{(2)}$ describes it as a clear, transparent plastic with a higher softening point and better impact strength than polystyrene. It is available in molding and extrusion composition, syrups, cast sheets, rods and tubes. In 1960 the consumption for molding and extrusion and in cast form was estimated at 85 million pounds.

\section{Properties of Polymethyl Methacrylate. Poly-} methyl methacrylate is a linear, atactic thermoplastic. Its structure is amorphous because of its bulky side groups and lack of stereoregularity(2). optical clarity and lack of color are its most outstanding properties. Coupled with unusually good outdoor weathering behavior, its optical properties make it highly useful in all applications where light transmission is important. An unusually wide range of brilliant, light-fast colors 
is available in this plastic.

Mechanical and thermal properties are also good. Tensile strength ranges as high as 10,000 pounds per square inch; heat distortion temperatures are above $90^{\circ} \mathrm{C}$ for heat resistant grades of polymethyl methacrylate. A limitation to the optical uses of the material is its poor abrasion resistance compared to glass. Uses of Polymethyl Methacrylate. Automotive uses (tail- and signal-light lenses, dials, etc.) consume more than half the polymethyl methacrylate molding powder produced ${ }^{(2)}$. Glass fiber-reinforced polymethyl methacrylate combines outstanding mechanical and weathering properties. The use of the polymer in paints and laquers is growing rapidly, accounting for about 27 million pounds in 1960.

Higher Methacrylates and Polyacrylates. Polylaurel methacrylate is widely used as a pour-point depressant and improver of viscosity-temperature characteristics of libricating oils (2). Polycyclohexyl methacrylate was developed to be combined with polystyrene in achromatic plastic lenses, the two polymers being similar in refractive index to crown and flint glass, respectively. Polycyclohexyl methacrylate is suitable for this application because of its relatively small shrinkage on polymerization: 12.5 versus 22 per cent for poly- 
methyl methacrylate.

The lower acrylates are rubbery and adhesive in nature. They contain an easily removed tertiary hydrogen atom and undergo some chain transfer to polymer when polymerized to high conversion. This leads to highly branched, insoluble polymer.

Selected Acrylic Polymers. In order to study the effect of the addition of side groups on the specific heat of acrylic polymers, the following polymers were selected because of the increasing complexity of their side groups: polyethyl acrylate, polymethyl methacrylate, polyallyl methacrylate, polydimethylaminoethyl methacrylate, and polycyclohexyl methacrylate. The structures of these polymers are presented in Figure 1, page 5 .

\section{Calorimetry and Specific Heat}

The drop calorimeter has been found to be a satisfactory tool for determining specific heats of polymers. This section contains descriptions of the drop calorimeter assembly, aluminum oxide specific heat determinations, the calorimeter section itself, specific heat estimations and available specific heats of polymethyl methacrylate. 
$\mathrm{OC}_{2} \mathrm{H}_{5} \quad \mathrm{OC}_{2} \mathrm{H}_{5}$
$\mathrm{O}=\mathrm{C}_{\mathrm{C}}^{\mathrm{C}} \mathrm{O}=\mathrm{C}_{\mathrm{C}}^{\mathrm{C}}-\mathrm{CH}_{2}-\underset{\mathrm{C}}{\mathrm{C}}-\mathrm{CH}_{2}-\mathrm{R}$
$\mathrm{H} \quad \frac{\mathrm{N}}{2}$

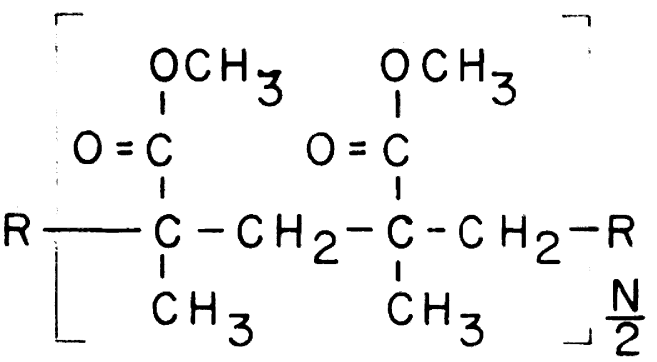

POLYETHYL

ACRYLATE
POLYMETHYL

METHACRYLATE<smiles>[R]CC(C)(CC(C)(C)C([R])(C)COCC=C)C(=O)OCC=C</smiles><smiles>[R]CC(C)(C(=O)OCC)C([R])(C)C</smiles>
POLYDIMETHYLAMINOETHYL METHACRYLATE<smiles>[R]CCCCCCCC([R])(C)C(=O)O</smiles>
POLYCYCLOHEXYL METHACRYLATE

FIGURE I. SELECTED 
The Drop Calorimeter Assembly. Southard ${ }^{(23)}$ has developed a calorimeter suitable for determining high temperature specific heats. The method consists of placing a sample into a capsule and heating it in a furnace to a determined temperature. At a given moment the sample is dropped into a calorimeter of known heat capacity. The sample capsule was a two by two centimeter cylinder of 0.2 millimeter 90 per cent platinum-10 per cent rhodium alloy.

The furnace had a heating element of a number twenty 80 per cent-20 per cent rhodium alloy wire wound on a one by fourteen inch alundum tube, surrounded by a water jacket, except for a one-inch hole at the top and bottom for passage of the capsule. The top hole was closed with a refractory plug three inches long and the bottom with a water-cooled gate. The heat exchanger with the calorimeter was made virtually zero even with the furnace at $1500^{\circ} \mathrm{C}$.

At $1100^{\circ} \mathrm{C}$ the temperature distribution in the furnace was such that a 1.25-inch length was isothermal to one degree by using a length to bore ratio of fourteen to one. The temperature of the capsule was measured by a platinum-platinum-10 per cent rhodium thermocouple.

The capsule was suspended by a number 32,90 per cent10 per cent rhodium alloy wire. The wire was led out through a small hole in the top of the furnace and 
attached to a steel plunger fastened by a spring trigger at the top of a long vertical brass tube. The brass tube was slotted throughout most of its length to permit free fall of the plunger. The last six inches were not slotted so that the fall of the plunger was checked by an air cushion.

The calorimeter was a gold plated cylindrical copper five by eight inch block, supported by three bakelite knife edges in a gold plated brass case. The calorimeter assembly was immersed in an oil bath maintained at 25.00 $\pm 0.01{ }^{\circ} \mathrm{C}$. The receiving well itself was in a removable tapered plug bearing a 100-ohm manganin wire heater, which was used in the electrical calibration of the heat capacity of the calorimeter.

An atmosphere of carbon dioxide was maintained in the calorimeter and furnace by a continuous flow of about 50 cubic centimeters per minute, which resulted in heat exchange rates amounting to $0.002^{\circ} \mathrm{C}$ per minute-degree. It was assumed that the loss of heat from the full capsule was the same as for the empty, during the time required for it to fall from the furnace to the calorimeter. A calorimeter of this type has recently been developed by Levinson (13) which is capable of measuring heat capacities in the range of $100-2500^{\circ} \mathrm{C}$. 


\section{Aluminum Oxide as a Standard. Ginnings and}

Corruccini (9) have determined specific heat and enthalpy data for aluminum oxide using a drop calorimeter. The furnace consisted of an alumaun tube (one inch inside diameter and 18 inches long), having a Chromel winding and surrounded by insulation. Auxilary heating units were used at each end of the furnace in order to provide an isothermal environment. At $1000^{\circ} \mathrm{C}$ gradients of only a few tenths of a degree per inch existed in the region where the sample was suspended.

The sample was contained in a Nichrome-5 capsule with a mass of 8.6 grams and a capacity of seven milliliters. The capsule was suspended about midway in the furnace by a number 32 Chromel wire. The drop was accomplished by the method of southard (23).

It has been calculated that, for a sample of average heat capacity, the difference between the amount of heat lost by the empty capsule during the drop and the amount of heat lost by the capsule and its sample will not exceed one calorie or 0.05 per cent of the enthalpy of the sample, and probably is less than 0.01 per cent in experiments below $1000^{\circ} \mathrm{C}$.

Experiments were performed in order to test the effectiveness of horizontal platinum shields for reducing heat losses up to the furnace. At $725^{\circ} \mathrm{C}$ in going by steps from one to four shields, the total range of 
variation of heat transferred to the calorimeter was 0.7 calories, the variation being largely random. With no shields the heat transferred was less by five calories. Thus one shield was considered satisfactory for confining heat losses up the tube.

The aluminum oxide used was in the form of polished rods of 0.02 to 0.03 per cent impurity, mostly silicon dioxide which has a specific heat close to that of the aluminum oxide.

The Calorimeter Section. Dole ${ }^{(5)}$ notes that a rectangular calorimeter is not satisfactory for high temperature determinations. Temperature gradients were discovered about the outer surface of the calorimeter during the heating period. Worthington (25) suggests that the ideal calorimeter should have a minimum surface to volume ratio and a minimum ratio of the heat capacity of the empty calorimeter to the heat capacity of its contents. Since a spherical calorimeter is mechanically impractical, a cylindrical one with a length to diameter ratio near unity is suggested.

Since full and empty calorimeter heating rates are different ${ }^{(5)}$, the heat capacity of the empty calorimeter should be calculated with the calorimeter empty and with it full of a substance of known heat capacity.

Precision of Measurements. Worthington (25) noted that the precision of specific heat measurements of high 
polymers decreased with increasing temperature, increased with increase of the specific heat of the polymer, and increased with weight of material in the calorimeter.

Specific Heat Estimations. Kopp's Rule ${ }^{(12)}$ states that the molar heat capacity of a solid at constant pressure and ordinary temperatures can be approximated by assuming it equal to the sum of its atomic heat capacities. Gambrill ${ }^{(7)}$ reports heat capacity contributions in calories per gram mole ${ }^{\circ} \mathrm{K}$ as: carhon, 1.8; hydrogen, 2.3; oxygen, 4.0; and nitrogen, 4.8. The specific heats for the selected polymers according to Kopp's Rule for solids are listed in Table VII, page 36 . Gambrill ${ }^{(8)}$ states that Kopp's Rule may be applied to liquids if the following atomic molar heats are used: carbon, 2.8; hydrogen, 4.3; oxygen, 6.0; and all others, 8.0. The results of this calculation are also found in Table VII, page 36.

A "linear continuum" theory has been postulated by Passaglia ${ }^{(17)}$. At temperatures below $55^{\circ} \mathrm{C}$ and above $-25^{\circ} \mathrm{C}$, linear polymers show a first power temperature dependence. The theory is based on a one-dimensional lattice model and has been shown to yield good agreement with experiment for polyethylene.

Johnson and Huang (II) have proposed an additive method for estimating specific heats of organic liquids 
based on atomic group heat capacities. These capacities are listed in Table VI, page 34 , and the results of this calculation are found in Table VII, page 36. This method permits the estimation of heat capacities at $20^{\circ} \mathrm{C}$. Watson's density expansion factor can be used to correlate the effect of temperature on specific heat. The critical temperature and pressure and a constant dependent on the nature of the compound are necessary to employ this correlation.

Chow and Bright ${ }^{(3)}$ have related the specific heat of a liquid with its parachor and molar refraction by means of an empirical equation. Average and maximum deviations of 1.9 and 7.6 per cent were observed for 74 organics of many types.

Sakiadis and Coates ${ }^{(18)}$ have proposed a method of estimating specific heats of organic liquids based on quantum mechanical considerations. Their equation is: 


$$
C_{v}=(6+a) R+\Sigma q_{i} C v_{i} \frac{3 n-6-a-\Sigma q_{i}}{\Sigma q_{i}}(s) \Sigma q_{i} C \delta{ }_{i}
$$

where:

$$
\begin{aligned}
& \mathrm{C}_{\mathrm{v}}=\text { heat capacity at constant volume, } \\
& \mathrm{cal} / \mathrm{gm} \text { mole- }{ }^{\circ} \mathrm{K} \\
& a=\text { number of bonds which may rotate freely; } \\
& \text { i.e., } \mathrm{C}-\mathrm{C} \text { or } \mathrm{C}-\mathrm{O} \text { in esters or ethers } \\
& q_{i}=\text { number of valence bonds of the } i^{\text {th }} \text { type } \\
& \mathrm{n}=\text { number of atoms in the molecule } \\
& C v_{i}, C \delta_{i}=\text { Einstein functions for stretching and for } \\
& \text { deformation } \\
& S=\text { correction factor, a function of molecular } \\
& \text { weight and type of compound } \\
& \mathrm{R}=\text { universal gas constant. }
\end{aligned}
$$

One may calculate the Einstein functions from the fundamental stretching or deformation frequency and the temperature. The knowledge of molecular structure and Sakiadis' correction factor permits the calculation of $\mathrm{C}_{\mathrm{v}}$.

Available Specific Heats. Warfield and Petree (24) have calculated from published data the entropy, enthalpy, and Gibbs free energy of polymethyl methacrylate over the range $0-260^{\circ} \mathrm{K}$. Bernhardt ${ }^{(1)}$ has published specific heats of polymethyl methacrylate at 80,210 , and $305^{\circ} \mathrm{F}$, shown in Figure 2, page 13. Specific heats may be 


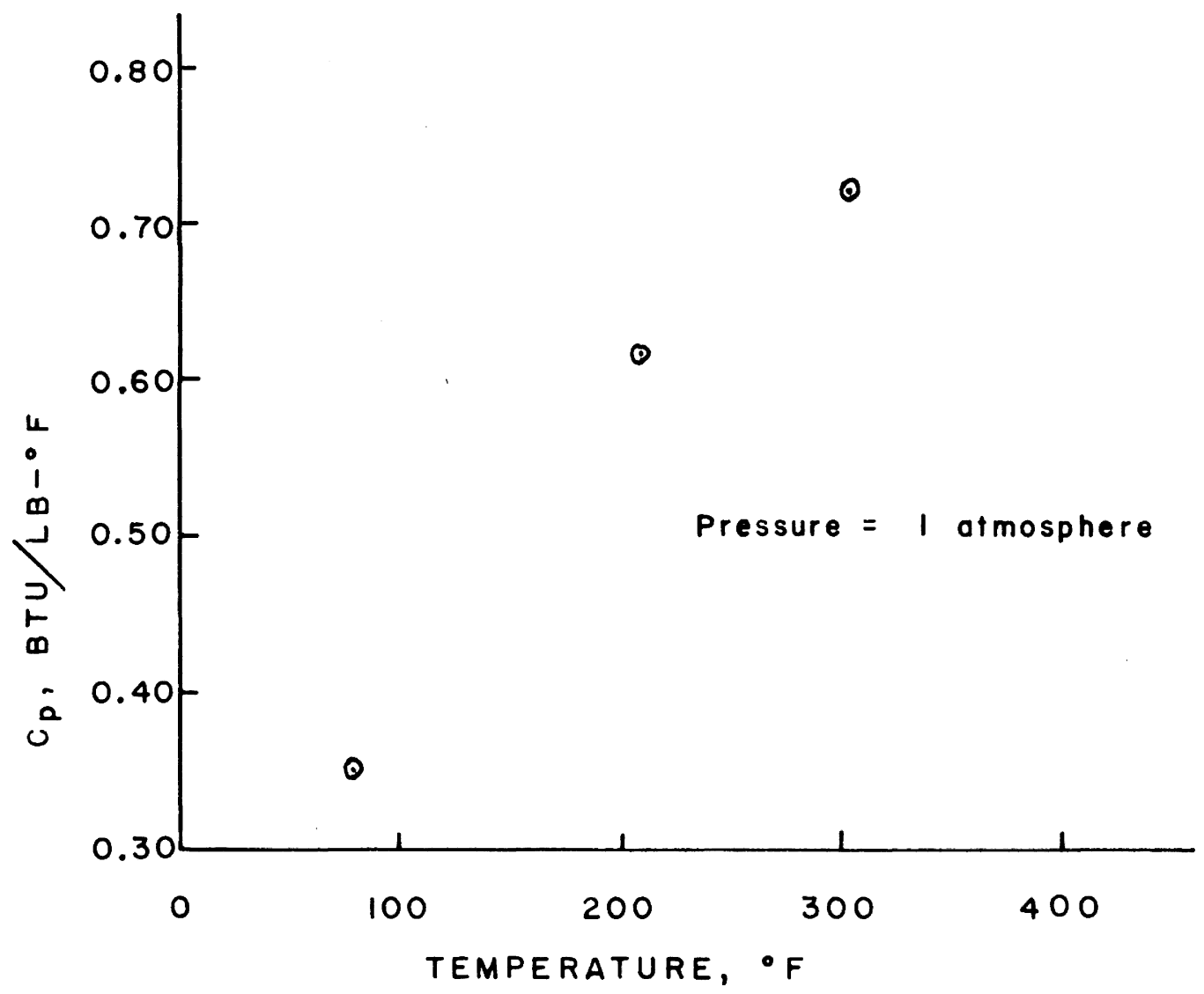

LUCITE 140 ACRYLIC RESIN (POLYMETHYL METHACRYLATE, ASTM GRADE 8)

DENSITY af $23^{\circ} \mathrm{C}=74.1 \mathrm{Ib} / \mathrm{ft} \mathrm{S}^{\circ}$

FIGURE 2. SPECIFIC HEAT OF POLYMETHYL METHACRYLATE AT HIGH TEMPERATURES

Bernhardt, E.C. : "Processing of Thermoplastic Materials", p. 559. Reinhold Publishing Corporation, New York, N. Y. , 1959. 
determined by numerically differentiating enthalpy data (10). Dainton ${ }^{(4)}$ has reported the specific heat of polymethyl methacrylate from 16 to $60^{\circ} \mathrm{K}$ (measured by Sochava ${ }^{(21)}$ ), and from 60 to $260^{\circ} \mathrm{K}$ (measured by Sochava and Trapeznikova $(22)$. These data are presented in Table $I$, page 15 . Using the drop calorimeter built by the Chemical Fngineering Department of Virginia Polytechnic Institute, Blacksburg, Virginia, Foster ${ }^{(6)}$ determined specific heat and enthalpy data for polyethylene, polypropylene and ethylene-propylene copolymer after checking Dole's (26) data. Using the same calorimeter, Haug ${ }^{(10)}$ determined the enthalpy of Nylon $6-10$ at $300^{\circ} \mathrm{C}$ and calculated specific heats at 285,290295 , and $300^{\circ} \mathrm{C}$.

Smith and Dole (19) have measured specific heats of polyethylene terephthalate (Dacron) from -20 to $300^{\circ} \mathrm{C}$. The change of the function $C_{p} / T$ at the glass temperature was shown to be roughly proportional to the fraction of amorphous polymer present. 
TABLE I.

Specific Heat and Enthalpy of Polymethyl

Methacrylate at Low Temperatures

\begin{tabular}{|c|c|c|}
\hline $\begin{array}{c}\text { Temperature } \\
\mathrm{O}_{\mathrm{K}}\end{array}$ & $\begin{array}{l}\text { Specific Heat } \\
\mathrm{cal} / \mathrm{gm}-\mathrm{oK}\end{array}$ & $\begin{array}{c}\text { Enthalpy } \\
\text { cal/gm }\end{array}$ \\
\hline $\begin{array}{l}10 \\
20 \\
30 \\
40 \\
50\end{array}$ & $\begin{array}{l}0.004 \\
0.009 \\
0.035 \\
0.051 \\
0.066\end{array}$ & $\begin{array}{l}0.01 \\
0.15 \\
0.40 \\
0.83 \\
1.41\end{array}$ \\
\hline $\begin{array}{r}60 \\
70 \\
80 \\
90 \\
100\end{array}$ & $\begin{array}{l}0.083 \\
0.098 \\
0.111 \\
0.126 \\
0.139\end{array}$ & $\begin{array}{l}2.16 \\
3.05 \\
4.11 \\
5.30 \\
6.63\end{array}$ \\
\hline $\begin{array}{l}110 \\
120 \\
130 \\
140 \\
150\end{array}$ & $\begin{array}{l}0.148 \\
0.157 \\
0.166 \\
0.175 \\
0.186\end{array}$ & $\begin{array}{r}8.07 \\
9.59 \\
11.21 \\
12.92 \\
14.73\end{array}$ \\
\hline $\begin{array}{l}160 \\
170 \\
180 \\
190 \\
200\end{array}$ & $\begin{array}{l}0.194 \\
0.202 \\
0.210 \\
0.218 \\
0.225\end{array}$ & $\begin{array}{l}16.63 \\
18.61 \\
20.67 \\
22.80 \\
25.01\end{array}$ \\
\hline $\begin{array}{l}210 \\
220 \\
230 \\
240 \\
250\end{array}$ & $\begin{array}{l}0.235 \\
0.243 \\
0.250 \\
0.255 \\
0.261\end{array}$ & $\begin{array}{l}27.32 \\
29.71 \\
32.18 \\
34.71 \\
37.30\end{array}$ \\
\hline $\begin{array}{l}260 \\
270 \\
273.15 \\
280 \\
290 \\
298.15 \\
300\end{array}$ & $\begin{array}{l}0.266 \\
0.271 \\
0.273 \\
0.276 \\
0.281 \\
0.284 \\
0.285\end{array}$ & $\begin{array}{l}39.93 \\
42.62 \\
43.48 \\
45.36 \\
48.14 \\
50.45 \\
50.98\end{array}$ \\
\hline
\end{tabular}

Dainton, F.S., D.M. Evans, F.E. Hoare and J.P. Melia (Univ. Leeds, Engl.): Thermodynamic Functions of Linear High Polymers VIII. Methyl Methacrylate and Polymethyl Methacrylate, Polymer, 3,317 (1962). 


\section{EXPERIMENTAL}

This section contains the plan of experimentation, the materials and apparatus, the method of procedure, the data, results and sample calculations relating to the determination of the calorimetric behavior of acrylic polymers.

\section{Plan of Experimentation}

The first experimental step in this study was the bulk polymerizations of the selected acrylic monomers. Test tube polymerizations in a water bath at $80^{\circ} \mathrm{C}$ using benzoyl peroxide as a catalyst were satisfactory.

Determination of the enthalpies of the polymers at five temperatures between 120 and $300^{\circ} \mathrm{C}$ was accomplished with the drop calorimeter constructed by the Chemical Engineering Department, Virginia Polytechnic Institute. Point calibrations were performed using vitrious silica. The resulting enthalpy data were numerically differentiated to obtain specific heats. Existing theories for the estimation of solid and liquid heat capacities were applied in an effort to explain the results. A method for predicting polymer heat capacities based on molecular structure was sought. 


\section{Materials}

Allyl Methacrylate. SR-201, lot no. 132-202-10. Manufactured by Sartomer Resins, Inc., Essington, Pa. Used as a material under study after polymerization.

Alphachloronaphthalene. Purity unknown. Obtained from the Chemical Engineering Department, Virginia Polytechnic Institute, Blacksburg, Virginia. Used in thermobulb to regulate furnace temperature at $250^{\circ} \mathrm{C}$.

Alumina, Activated. Grade F-20. Manufactured by the Aluminum Company of America, East St. Louis, Illinois, Used as an absorbant for purifying monomers.

Benzoyl Peroxide. Lot 793486 , reagent grade. Manufactured by Fisher Scientific Company, Fairlawn, N.J. Used as a catalyst for polymerizing monomers. Butyl Acetate, Normal. Purity unknown, boiling point $126^{\circ} \mathrm{C}$. Obtained from the Chemical Engineering Department, Virginia Polytechnic Institute, Blacksburg, Va. Used in thermobulb to regulate calorimeter furnace at $120^{\circ} \mathrm{C}$.

Cyclohexyl Methacrylate. SR-208, lot no. 132-173-

19. Manufactured by Sartomer Resins, Inc., Essington, $\mathrm{Pa}$. Used as material under study after polymerization. Dimethylaminoethyl Methacrylate. Lot no. 4527, inhibited with 2000 parts per million MEHQ. Manufactured by Rohm and Haas Company, Philadelphia, Pa. Used as a 
material under study after polymerization.

Ethyl Acrylate. Lot no. 7631, inhibited with 15 parts per million MEHQ. Manufactured by Rohm and Haas Company, Philadelphia, Pa. Used as material under study after polymerization.

Ethyl Phthalate. Lot no. 794457, purified, boiling point $298^{\circ} \mathrm{C}$. Manufactured by Fisher Scientific Company, Fairlawn, N.J. Used in thermobulb to regulate calorimeter furnace temperature at $300^{\circ} \mathrm{C}$.

Ice. Obtained from the Chemical Engineering Department, Virginia Polytechnic Institute, Blacksburg, Va. Used in Dewar flasks for thermopile cold junctions.

Methyl Methacrylate. Lot 6928, inhibited with 35 parts per million BHT. Manufactured by Rohm and Haas Company, Philadelphia, Pa. Used as material under study after polymerization.

Methyl n-Amyl Ketone. Purity unknown, boiling point $151.5^{\circ} \mathrm{C}$. Obtained from the Chemical Engineering Department, Virginia Polytechnic Institute, Blacksburg, Va. Used in thermobulb to regulate calorimeter furnace temperature at $150^{\circ} \mathrm{C}$.

Mercury. Obtained from the Chemical Engineering Department, Virginia Polytechnic Institute, Blacksburg, Va. Used in thermobulb for calorimeter furnace temperature control. 
Oil, Heavy. Circo Xxx. Obtained from the Chemical Engineering Department, Virginia Polytechnic Institute, Blacksburg, Va. Used as bath to heat calorimeter furnace.

Orthotoluidine. Purity unknown. Obtained from the Chemical Engineering Department, Virginia Polytechnic Institute, Blacksburg, Va. Used in thermobulb to regulate calorimeter furnace temperature at $190^{\circ} \mathrm{C}$.

Water, Tap. Obtained from the town of Blacksburg, Va. Used in calorimeter as medium for absorbing heat from polymer sample and capsule.

\section{Apparatus}

Calorimeter, Drop. Assembled by the Chemical Engineering Department, Virginia Polytechnic Institute, Blacksburg, Va. Used to determine enthalpies of test materials.

Flasks, Dewar. Two 1000 milliliter. Obtained from the Chemical Engineering Department, Virginia Polytechnic Institute, Blacksburg, Va. Used to hold icewater mixtures for thermopile cold junctions.

Oven, Drying. Model 0V-8, serial no. 8-264, 115 volts, 5 amps. Manufactured by Modern Electric Laboratory, Chicago, Ill. Used to cure polymer samples. Powerstat. Type 3PNl16, ph. 1.0, pri. voltage 
120 volts, 50/60 cycles, out. voltage 0-140 volts, max. amps 7.5, max. kva 1.0. Manufactured by Superior Electric Company, Bristol, Conn. Distributed by Fisher Scientific Company, Pittsburgh, Pa. Used to regulate power to calorimeter furnace heater.

Recorder, Temperature. Speedomax "H" model. Manufactured by Leeds and Northrup, Philadelphia, Pa. Used to measure and record emf differences of thermopiles in furnace and calorimeter.

Regulator, Temperature. Model B, serial no. 5712, 115 volts, 60 cycles, 10 amps. Manufactured by Eastern Industries, Inc., Hamden, Conn. Used to regulate heater in calorimeter furnace.

Stirrer, Mechanical. Fultork Labmotor model, 115 volts, 60 cycle. Manufactured by Fisher Scientific Company, Pittsburgh, $\mathrm{Pa}$. Used to stir water bath for polymerizations.

Test Tubes, Pyrex. Five, 20 x 150 millimeters. Obtained from the Chemical Engineering Department, Virginia Polytechnic Institute, Blacksburg, Va. Used as containers for polymerizing monomers.

Timer Electric. Indicates seconds and tenths of seconds, 115 volts, 60 cycles, 5 watts. Manufactured by Fisher Scientific Company, Pittsburgh, Pa. Used to measure time for heat transfer from sample to calorimeter. 
Wire, Nichrome. Size 0063, grade E, 16,77 ohms per foot. Manufactured by Wilbur B. Driver Company, Newark, N.J. Used to suspend sample capsule in calorimeter. 


\section{Method of Procedure}

The experimental procedure was divided into three sections: the monomer polymerizations, calibrations, and the calorimetric determinations.

Polymerizations. In order to obtain compact, airfree polymers, a transfer mold was designed and constructed. The mold consisted of two cylindrical chambers separated by an orifice through which molten polymer could be forced into the lower chamber. Ten thousand pounds force was exerted by a Carver press on a brass plunger which forced the molten polymer, initially in the 5/8-inch diameter upper chamber, through the orifice into the lower chamber. Samples contained air bubbles and stuck to the molding chamber even when silicone mold release was used. Removal of samples was difficult; melt fracture was observed in several samples.

Test tube bulk polymerizations were found to yield satisfactory results. The monomers were placed in 20 by 150 millimeter test tubes and mixed with 0.05 grams of benzoyl peroxide per 100 grams of monomer. The samples were placed in a stirred water bath at $80^{\circ} \mathrm{C}$ until polymerized. The test tubes were broken and the samples were placed in an oven at $160^{\circ} \mathrm{F}$ overnight to insure complete polymerization. The polymers were then cut into 5/8-inch diameter cylinders, 1-1/4 inches in length to fit the sample capsule in the drop 
calorimeter. The polyethyl acrylate sample was slightly rubbery after curing and was cut with a knife in the shape of a half cylinder in order that it fit the sample capsule. It could not have been easily machined down to the required 5/8-inch diameter.

Calibrations. Two thermopiles for measuring the furnace temperature and calorimeter temperature were constructed. The former was a three-couple pile of ironconstantan; the latter was a six-couple pile of copperconstantan. Water, ice, acetone, tin, and lead were used to obtain the needed calibrations.

By measuring the calorimeter temperature and room temperature as functions of time, the heat transfer coefficient for heat transfer from the calorimeter to the room was calculated. Radiation and conduction of heat to the calorimeter were neglected.

The effective enthalpy changes of the capsule were determined in the same manner as a sample test, described in the following section. The enthalpy change of the full capsule was assumed the same as for the empty capsule ${ }^{(23)}$. Thermopile $\mathrm{Tl}$, shown in Figure 3, page 24, was positioned in the calorimeter $\underline{D}$ so that the correct value for the known enthalpy of vitreous silica was obtained. Calorimetric Determinations. The drop calorimeter used for this experiment is shown in Figure 3, page 24 . 
$-24-$

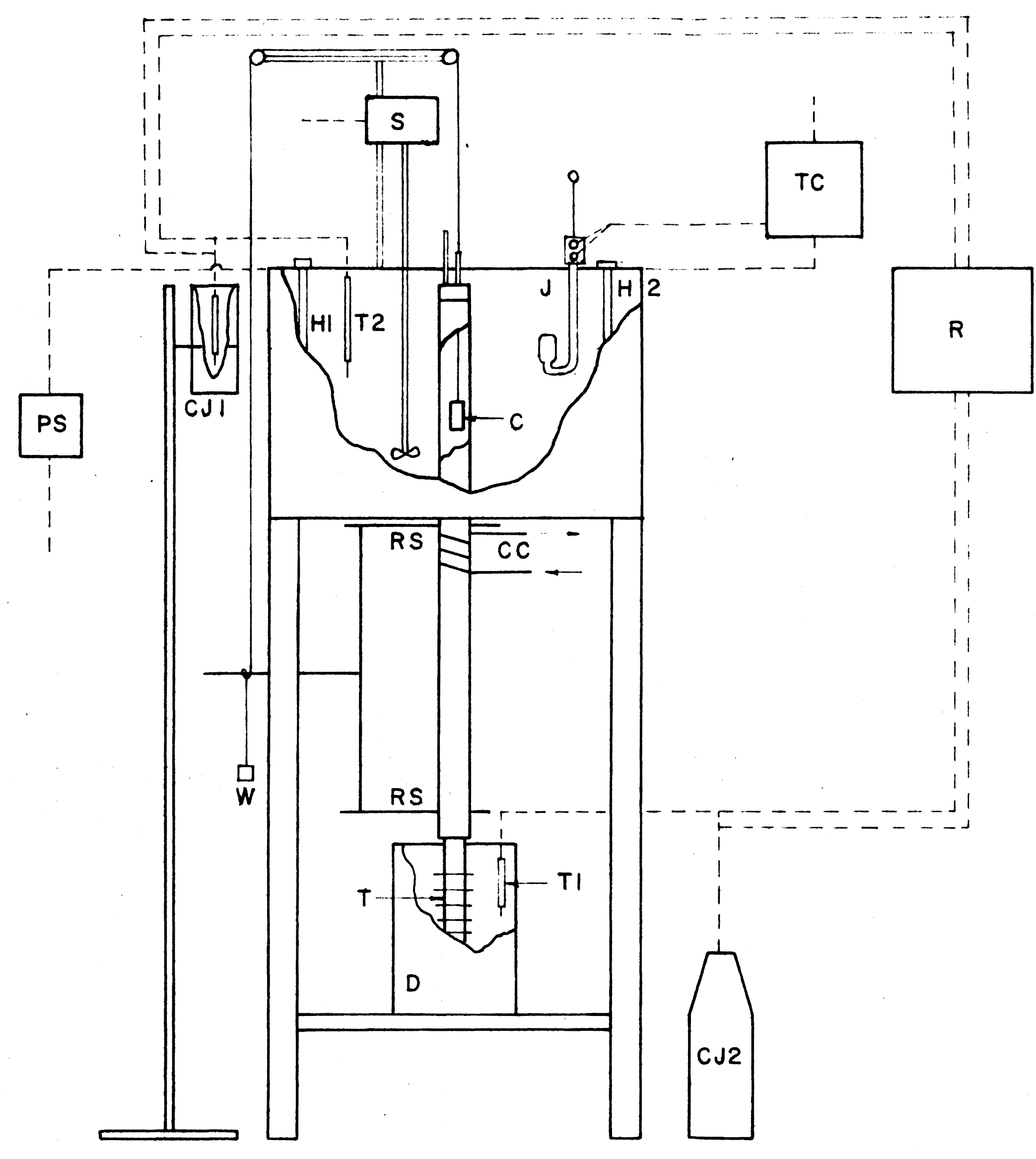

\section{LEGEND}

SAMPLE CAPSULE

COOLING COIL

COLD JUNCTION

DEWAR FLASK

HEATER

THERMOBULB

POWERSTAT

RECORDER

RADIATION SHIELD

STIRRER

CALORIMETER TUBE

TEMPERATURE CONTROLLER

THERMOPILES

WEIGHT

DEPARTMENT OF CHEMICAL ENGINEERING VIRGINIA POLYTECHNIC INSTITUTE BLACKSBURG, VIRGINIA

FIGURE 3. DROP CALORIMETER 
A sensitive fluid was placed in the tip of the J-tube thermobulb, the remainder of which was filled with mercury. A fluid which boils near the desired control temperature was selected to obtain the proper sensitivity. Enthalpies were measured at $120,150,190,250$, and $300^{\circ} \mathrm{C}$ based on $15^{\circ} \mathrm{C}$. Ice-water mixtures were placed in Dewar flasks CJI and CJ2 and the thermopile cold junctions were placed in the mixtures. After starting stirrer $\underline{S}$, the oil bath was heated with heaters $\underline{H I}$ and $\underline{H 2}$ until a sinusoidal curve of amplitude less than $0.3^{\circ} \mathrm{C}$ was observed on the recorder. The furnace temperature was measured with thermopile T2. The weighed sample was placed in the capsule $\underline{C}$ and suspended in the furnace for two hours. Then the Dewar flask $\underline{D}$ was filled with one liter of tap water measured with a graduated cylinder. The average furnace temperature and the initial calorimeter temperature were recorded.

The sample was dropped into the finned tube $\underline{T}$. The room temperature ard the temperature of the water measured by $\underline{T l}$ were recorded 15 minutes after the drop. The aforementioned data, along with the heat transfer coefficient for heat transfer from the calorimeter to the room and the sample capsule permitted the calculation of the enthalpy change of the sample between the furnace temperature and the final calorimeter temperature. 


\section{Data and Results}

The data and results are presented in tabular and graphical form herein. Sample calculations are included to provide clarity.

Calorimeter Data. The system constants and raw calorimetric data are presented in Tables II and III, pages 27 , and 28 , respectively. Sample enthalpies are plotted in Figure 4, page 29. The smoothed enthalpies are presented in Table IV, page 30 .

Specific Heats. The specific heats of the polymers are found in Table $V$, page 31 , and in Figures 5 and 6 , pages 32 and 33 , respectively.

Estimations and Correlations. Results of a correlation method are found in Table VI, page 34 , and plotted in Figure 7, page 35. Atomic group heat capacity contributions are listed in Table VII, page 36. Estimations for normal temperatures are found in Table VIII, page 37. Modified correction factors for Sakiadis and Coates' method are listed in Table IX, page 38, and plotted against temperature and mer weight in Figures 8 and 9 , pages 39 and 40 , respectively. Specific heats estimated by this method are found in Table $x$, page 41 . 
TABLE II.

System Constants

Heat transfer coefficient for

heat transfer from calorimeter

to room for 15 minutes........... $57.75 \mathrm{cal} /{ }^{\circ} \mathrm{C}$

Mean specific heat of water

in calorimeter................. $1000 \mathrm{cal} /{ }^{\circ} \mathrm{C}$

Mean specific heats of sample capsule

Temperature

${ }^{\circ} \mathrm{C}$

120

150

190

250

300
Mean specific heat

$$
\mathrm{cal} /{ }^{\circ} \mathrm{C}
$$

2.74

4.33

4.82

5.08

5.38 
TABLE III.

\section{Calorimeter Data}

\begin{tabular}{|c|c|c|c|c|c|c|c|c|c|}
\hline $\begin{array}{l}\text { Test } \\
\text { No. }\end{array}$ & Polymer & $\begin{array}{l}\text { Sample } \\
\text { Weight }\end{array}$ & $\begin{array}{l}\text { Furnace } \\
\text { Temp }\end{array}$ & $\begin{array}{l}\text { Calo } \\
\text { Temp } \\
\text { Before } \\
{ }_{\mathrm{C}}\end{array}$ & $\begin{array}{c}\text { After } \\
{ }^{\circ} \mathrm{C}\end{array}$ & $\begin{array}{c}\text { Average } \\
\text { Temperature } \\
\text { of } \\
\text { Calorimeter } \\
{ }_{\text {O }}\end{array}$ & $\begin{array}{l}\text { Room } \\
\text { Temp. }\end{array}$ & Enthalpy & $\begin{array}{c}\text { Corrected } \\
\text { Enthalpy }\end{array}$ \\
\hline 1 & PMMA & 5.5316 & 121.1 & 16.14 & 17.17 & 16.65 & 22.0 & 79.8 & 80.6 \\
\hline 2 & PMMA & 5.0910 & 151.0 & 16.46 & 17.98 & 17.22 & 24.5 & 102.7 & 104.2 \\
\hline 3 & PMMA & 5.0910 & 190.8 & 16.07 & 17.78 & 16.92 & 21.0 & 125.5 & 126.9 \\
\hline 4 & PMMA & 5.0910 & 250.1 & 16.55 & 18.92 & 17.73 & 22.0 & 187.0 & 190.1 \\
\hline 5 & PMMA & 2.7912 & 302.2 & 16.87 & 19.57 & 18.22 & 25.0 & 282.0 & 282.0 \\
\hline 6 & PDMAFMA & 4.6610 & 120.3 & 14.24 & 15.40 & 14.82 & 24.2 & 71.2 & 71.2 \\
\hline 7 & PDMAEMA & 4.6610 & 150.9 & 15.83 & 17.42 & 16.63 & 27.4 & 38.8 & 84.7 \\
\hline 8 & PDMAEMA & 4.6610 & 191.0 & 15.42 & 17.18 & 16.30 & 24.1 & 101.0 & 101.7 \\
\hline 9 & PDMAEMA & 4.6610 & 250.0 & 15.99 & 18.45 & 17.22 & 28.1 & 141.3 & 143.4 \\
\hline 10 & PDMAEMA & 4.6610 & 303.9 & 15.61 & 18.20 & 16.90 & 27.2 & 240.2 & 242.0 \\
\hline 11 & PCHMA & 6.1209 & 121.2 & 12.48 & 13.89 & 13.18 & 25.6 & 65.6 & 64.2 \\
\hline 12 & PCHMA & 6.1209 & 150.0 & 15.77 & 17.20 & 16.49 & 27.4 & 69.5 & 70.6 \\
\hline 13 & PCHMA & 6.1209 & 190.8 & 16.32 & 18.21 & 17.26 & 26.0 & 106.6 & 108.1 \\
\hline 14 & PCHMA & 5.7917 & 250.1 & 14.69 & 16.93 & 15.81 & 21.6 & 125.0 & 126.0 \\
\hline 15 & PAMA & 6.1902 & 120.3 & 15.84 & 17.01 & 16.42 & 25.9 & 54.4 & 55.3 \\
\hline 16 & PAMA & 6.6145 & 150.0 & 16.10 & 17.63 & 16.86 & 27.6 & 65.8 & 67.1 \\
\hline 17 & PAMA & 6.1902 & 190.9 & 15.99 & 17.79 & 16.89 & 24.6 & 84.2 & 85.1 \\
\hline 18 & PAMA & 6.1902 & 250.1 & 15.22 & 17.42 & 16.32 & 20.2 & 127.0 & 128.2 \\
\hline 19 & PAMA & 6.1902 & 302.3 & 18.47 & 21.58 & 20.02 & 28.4 & 178.0 & 180.7 \\
\hline 20 & PEA & 2.5377 & 120.4 & 14.48 & 15.53 & 15.00 & 25.0 & 74.5 & 74.5 \\
\hline 21 & PEA & 2.5377 & 150.8 & 14.82 & 16.25 & 15.53 & 26.9 & 75.5 & 75.7 \\
\hline 22 & PEA & 2.5377 & 190.7 & 14.82 & 16.38 & 15.60 & 23.9 & 94.8 & 95.2 \\
\hline 23 & $\mathrm{PEA}$ & 2.5377 & 250.0 & 13.78 & 15.93 & 14.85 & 26.4 & 115.8 & 115.8 \\
\hline 24 & PEA & 2.1240 & 301.9 & 13.03 & 15.70 & 14.37 & 28.6 & 144.3 & 143.2 \\
\hline
\end{tabular}




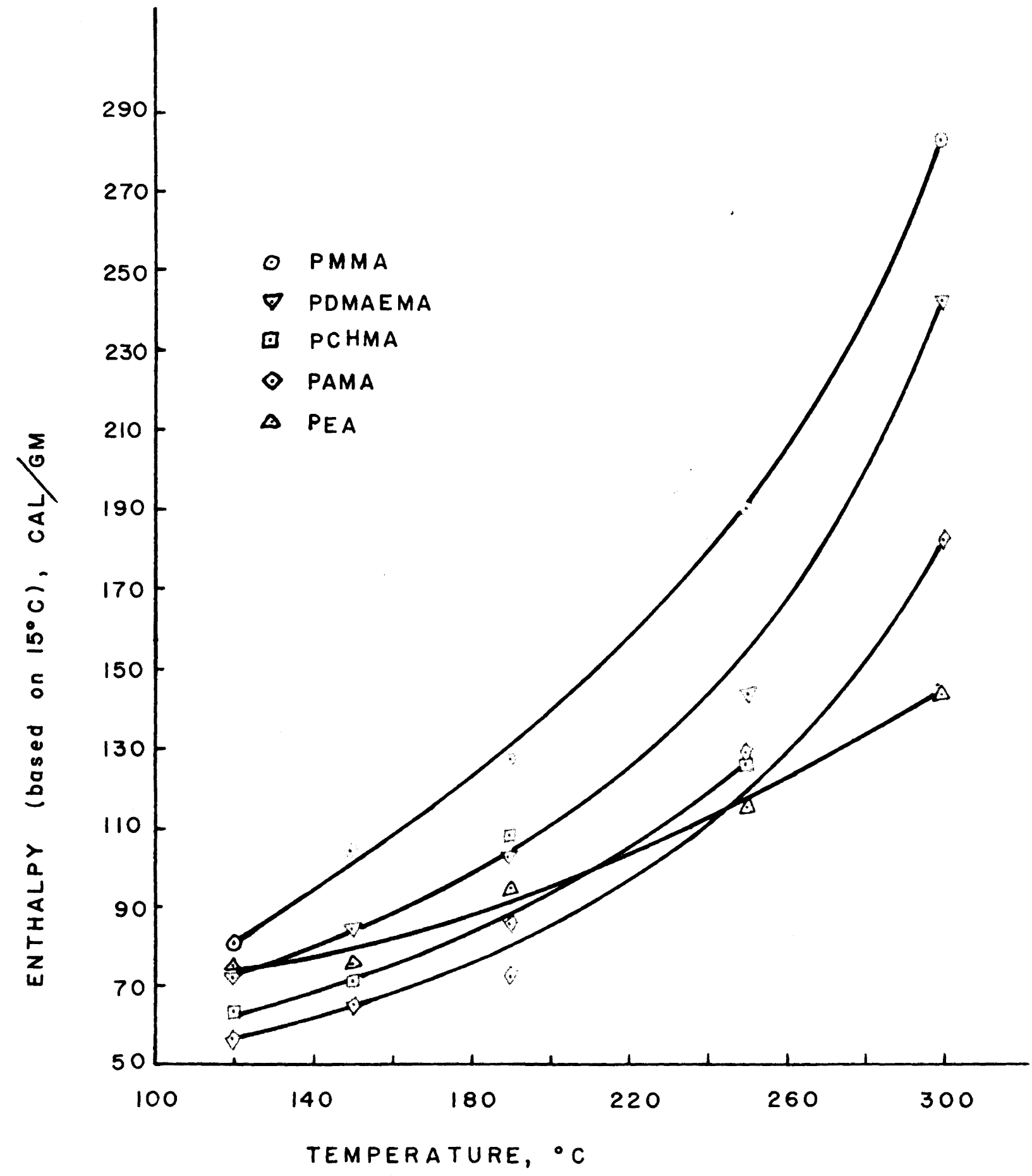

FIGURE 4. ENTHALPIES OF SELECTED POLYMERS 
TABLE IV.

Smoothed Enthalnies of Selected Polymers

\begin{tabular}{cccccc}
\hline $\begin{array}{c}\text { Temperature } \\
{ }^{\circ} \mathrm{C}\end{array}$ & PMMA & PDMAEMA & PCHMA & PAMA & PFA \\
\hline 120 & 74 & 72 & 64 & 60 & 75 \\
150 & 100 & 85 & 72 & 66 & 80 \\
180 & 123 & 99 & 83 & 76 & 88 \\
210 & 149 & 118 & 98 & 90 & 99 \\
240 & 180 & 142 & 118 & 111 & 112 \\
270 & 220 & 177 & $146^{\mathrm{b}}$ & 141 & 128 \\
300 & 282 & 242 & $195^{\mathrm{b}}$ & 182 & 144 \\
\hline
\end{tabular}

a Units are cal/gm- ${ }^{\circ} \mathrm{C}$ based on $15^{\circ} \mathrm{C}$

b Extrapolated above $250^{\circ} \mathrm{C}$ 
TABLE V.

Specific Heats of Selected Polymers

\begin{tabular}{|c|c|c|c|c|c|c|c|c|}
\hline \multirow[t]{2}{*}{ Polymer } & \multirow[t]{2}{*}{ Method } & \multicolumn{7}{|c|}{ Temperature, ${ }^{\circ} \mathrm{C}$} \\
\hline & & 120 & 150 & 180 & 210 & 240 & 270 & 300 \\
\hline \multirow[t]{2}{*}{ PMMA } & $\mathrm{a}$ & $1.05^{\mathrm{d}}$ & 0.93. & 0.80 & 0.94 & 1.09 & 1.59 & 6.41 \\
\hline & $b$ & 0.66 & 0.75 & 0.80 & 0.89 & 1.12 & 1.54 & 2.52 \\
\hline \multirow[t]{2}{*}{ PDMAEMA } & a & 0.58 & 0.40 & 0.55 & 0.71 & 0.92 & 1.52 & 6.62 \\
\hline & $\mathrm{b}$ & 0.40 & 0.42 & 0.53 & 0.72 & 0.93 & 1.47 & 2.36 \\
\hline \multirow[t]{2}{*}{ PCHMA } & $a$ & 0.21 & 0.31 & 0.53 & 0.58 & 0.73 & $1.16^{\mathrm{C}}$ & $5.50^{\mathrm{C}}$ \\
\hline & $\mathrm{b}$ & 0.31 & 0.33 & 0.44 & 0.59 & 0.76 & $1.14^{\mathrm{C}}$ & $2.21^{\mathrm{C}}$ \\
\hline \multirow[t]{2}{*}{ PAMA } & a & 0.05 & 0.29 & 0.38 & 0.57 & 0.84 & 1.17 & 4.61 \\
\hline & $\mathrm{b}$ & 0.19 & 0.28 & 0.41 & 0.56 & 0.83 & 1.14 & 1.58 \\
\hline \multirow[t]{2}{*}{$\mathrm{PEA}$} & $a$ & 0.20 & 0.20 & 0.33 & 0.40 & 0.48 & 0.54 & 4.13 \\
\hline & $\mathrm{b}$ & 0.17 & 0.21 & 0.32 & 0.41 & 0.48 & 0.54 & 0.63 \\
\hline
\end{tabular}

\footnotetext{
a Milne's(14) seven point numerical differentiation.

b Measurement of slope of enthalpy - temperature curve

C Extrapolated above $250^{\circ} \mathrm{C}$.

d Units are cal $/ \mathrm{gm}-{ }^{\circ} \mathrm{C}$.
} 


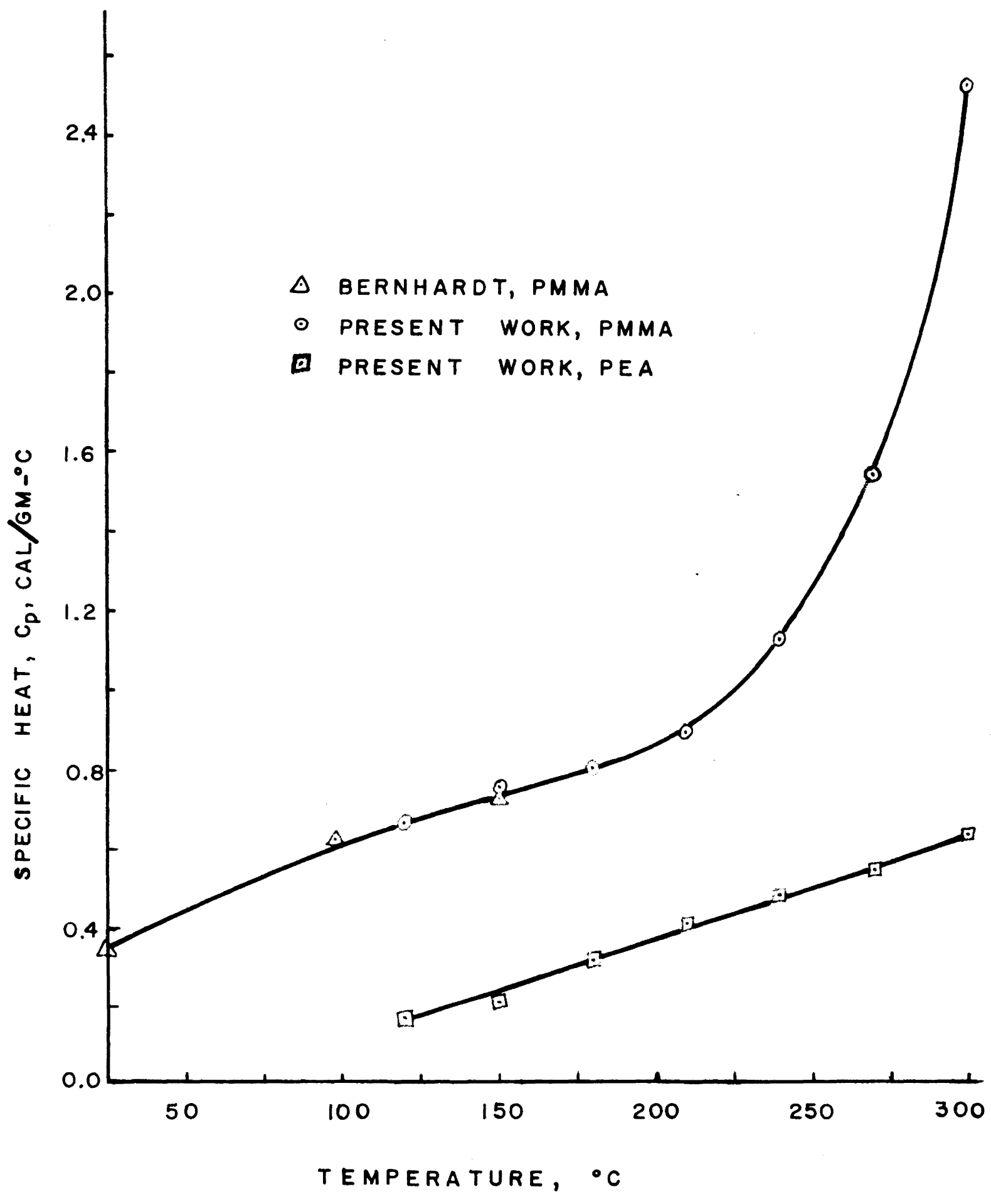

FIGURE 5. SPECIFIC HEATS OF POLYMETHYL METHACRYLATE AND POLYETHYL ACRYLATE 


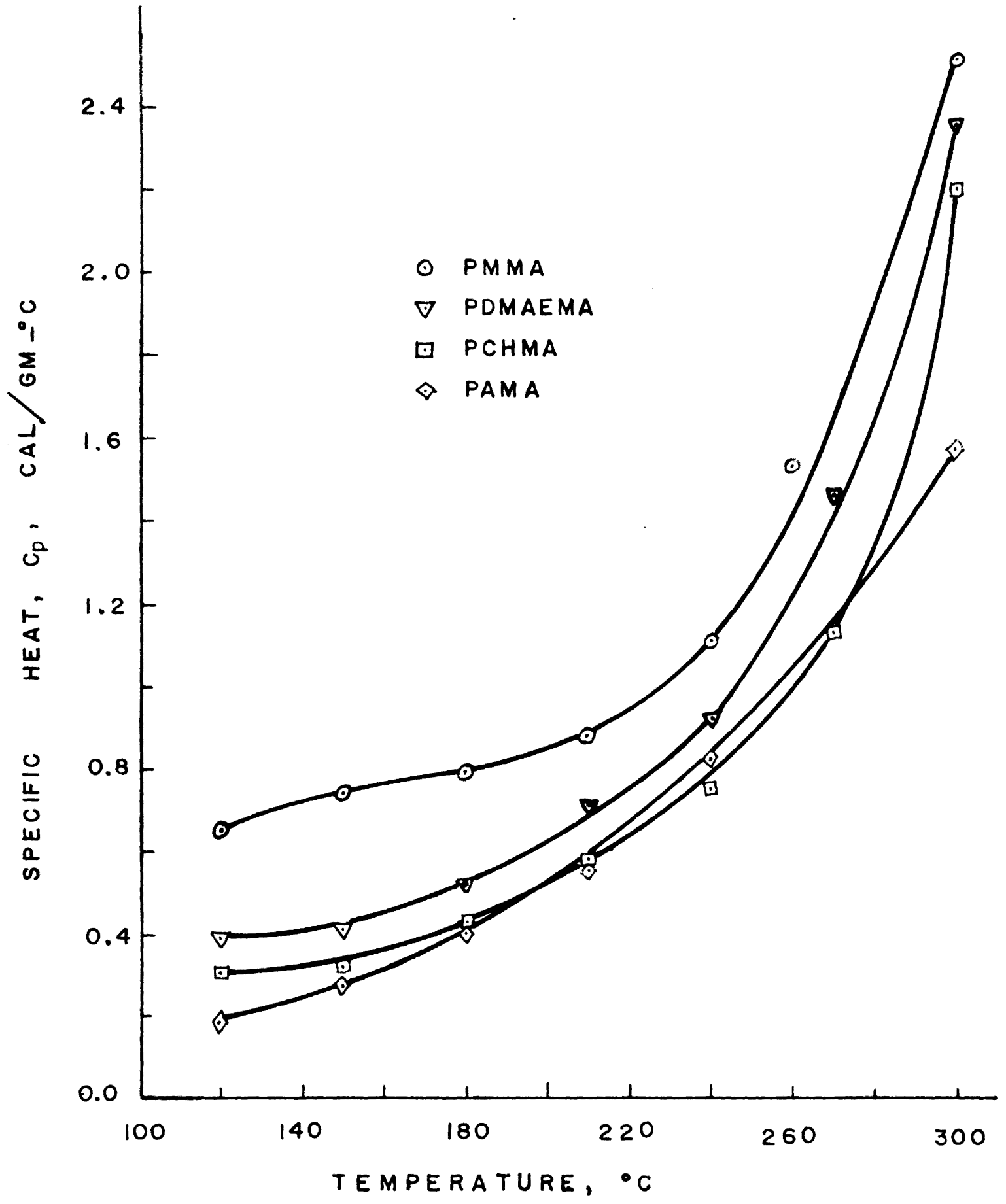

FIGURE 6. SPECIFIC HEATS OF METHACRYLICS 
TABLE VI.

Correlation of Specific Heats of Linear

Methacrylic polymers

\begin{tabular}{|c|c|c|c|}
\hline \multirow{2}{*}{$\begin{array}{c}\text { Temperature } \\
{ }^{\circ} \mathrm{C}\end{array}$} & \multicolumn{3}{|c|}{ Heat Capacity Function ${ }^{a}, C_{p}{ }^{120 / T}$} \\
\hline & PMMA & PDMAEMA & PCHMA \\
\hline 120 & 66.0 & 62.8 & 52.1 \\
\hline 150 & 30.0 & 24.2 & 19.8 \\
\hline 180 & 17.2 & 15.5 & 13.5 \\
\hline 210 & 12.4 & 13.0 & 11.0 \\
\hline 240 & 11.2 & 11.7 & 9.9 \\
\hline 270 & 12.0 & 14.0 & $11.2^{b}$ \\
\hline 300 & 15.9 & 17.9 & $17.2^{\mathrm{b}}$ \\
\hline
\end{tabular}

a Units are $\left(\mathrm{cal} / \mathrm{gm}^{\circ}{ }^{\circ} \mathrm{C}\right)(\mathrm{gm} / \mathrm{gm}$ mole mer), $\mathrm{T}$ in ${ }^{\circ} \mathrm{C}$

b Extrapolated above $250^{\circ} \mathrm{C}$. 


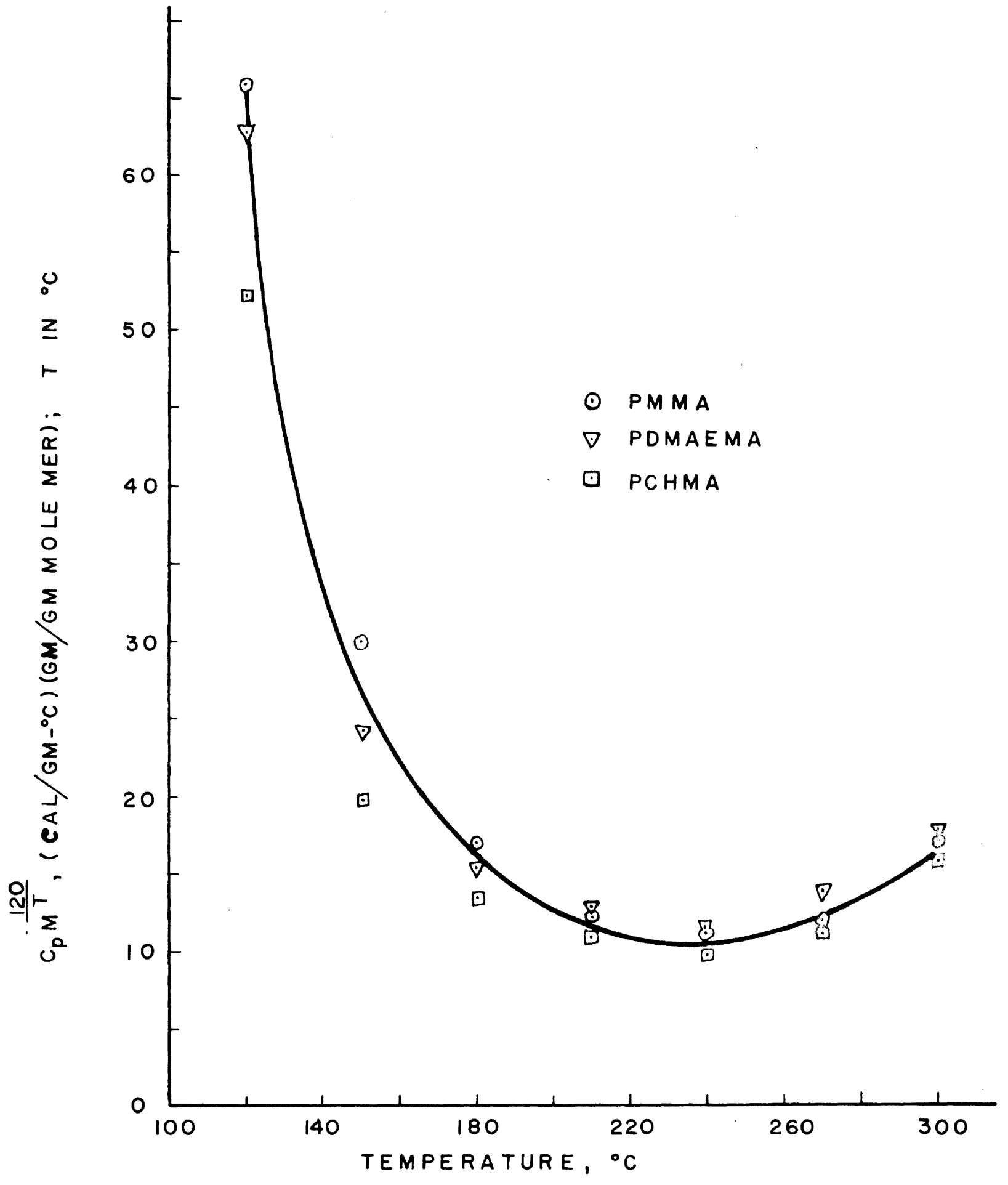

FIGURE 7. CORRELATION OF SPECIFIC HEATS OF LINEAR METHACRYLIC POLYMERS 
TABLE VII.

Atomic Group Heat Capacity Contributions

at $20^{\circ} \mathrm{C}$

\begin{tabular}{ccc}
\hline Group & \multicolumn{2}{c}{ Contribution } \\
& $\mathrm{cal} / \mathrm{gm}$ mole ${ }^{\circ} \mathrm{K}$ & $\mathrm{cal} / \mathrm{gm}-{ }^{\circ} \mathrm{K}$ \\
$\mathrm{CH}_{3}-$ & 9.9 & 0.66 \\
$-\mathrm{CH}_{2}-$ & 6.3 & 0.45 \\
$-\mathrm{C}-\mathrm{H}$ & 5.4 & 0.42 \\
$-\mathrm{COO}-$ (esters) & 14.5 & 0.33 \\
$\mathrm{C}_{6} \mathrm{H}_{5}-$ & 30.5 & 0.40 \\
$-\mathrm{NH}_{2}$ & 15.2 & 0.95 \\
\hline
\end{tabular}

Johnson, A.I., and C.J. Huang, Can. J. Technol., 33, 421 (1955). 
TABLE VIII.

Specific Heat Estimations at Normal Temperatures

\begin{tabular}{lcccc} 
Polymer & $\begin{array}{r}\text { Kopp's Rule } \\
\text { for Solids } \\
\mathrm{Cal} / \mathrm{gm}-{ }^{\circ} \mathrm{C}\end{array}$ & $\begin{array}{c}\text { Kopp's Rule } \\
\text { for Liquids } / \mathrm{gm}-{ }^{\circ} \mathrm{C}\end{array}$ & $\begin{array}{c}\text { Johnson and } \\
\text { Huang } \\
\mathrm{Cal} / \mathrm{gm}-{ }^{\circ} \mathrm{C}\end{array}$ & $\begin{array}{c}\text { Observed } \\
\mathrm{C}_{\mathrm{p}} \text { at } 120^{\circ} \mathrm{C} \\
\mathrm{Cal} / \mathrm{gm}-{ }^{\circ} \mathrm{C}\end{array}$ \\
\hline PMMA & 0.35 & 0.60 & 0.46 & 0.66 \\
PDMAEMA & 0.39 & 0.68 & 0.48 & 0.40 \\
PCHMA & 0.37 & 0.65 & $0.42^{\mathrm{a}}$ & 0.31 \\
PAMA & 0.35 & 0.59 & 0.43 & 0.19 \\
PEA & 0.35 & 0.60 & 0.43 & 0.17 \\
\end{tabular}

a This calculation was made assuming group heat contributions of $\mathrm{C}_{6} \mathrm{H}_{5}$ and $\mathrm{C}_{6} \mathrm{H}_{11}$ - are the same. 
TABLE IX.

Modified Correction Factors for Sakiadis

and Coates' Method for Polymers

\begin{tabular}{lcccc}
\hline Polymer & $\begin{array}{c}\text { Mer } \\
\text { Weight } \\
\frac{\text { gm }}{\text { gm mole mer }}\end{array}$ & \multicolumn{2}{c}{$\begin{array}{c}\text { Modified Correction Factor, } \\
\text { S, for polymer specific heats }\end{array}$} \\
\hline PMMA & $120^{\circ} \mathrm{C}$ & $210{ }^{\circ} \mathrm{C}$ & $300^{\circ} \mathrm{C}$ \\
PDMAEMA & 100 & 1.81 & 2.46 & 8.42 \\
PCHMA & 157 & 0.60 & 1.57 & 6.55 \\
PAMA & 168 & 0.41 & 1.24 & 5.75 \\
PEA & 126 & -0.27 & 1.31 & 4.35 \\
& 100 & -0.56 & 0.43 & 1.03 \\
\hline
\end{tabular}

a Correction factors calculated to produce agreement with experiment and the
method of Sakiadis and coates $(18)$. 


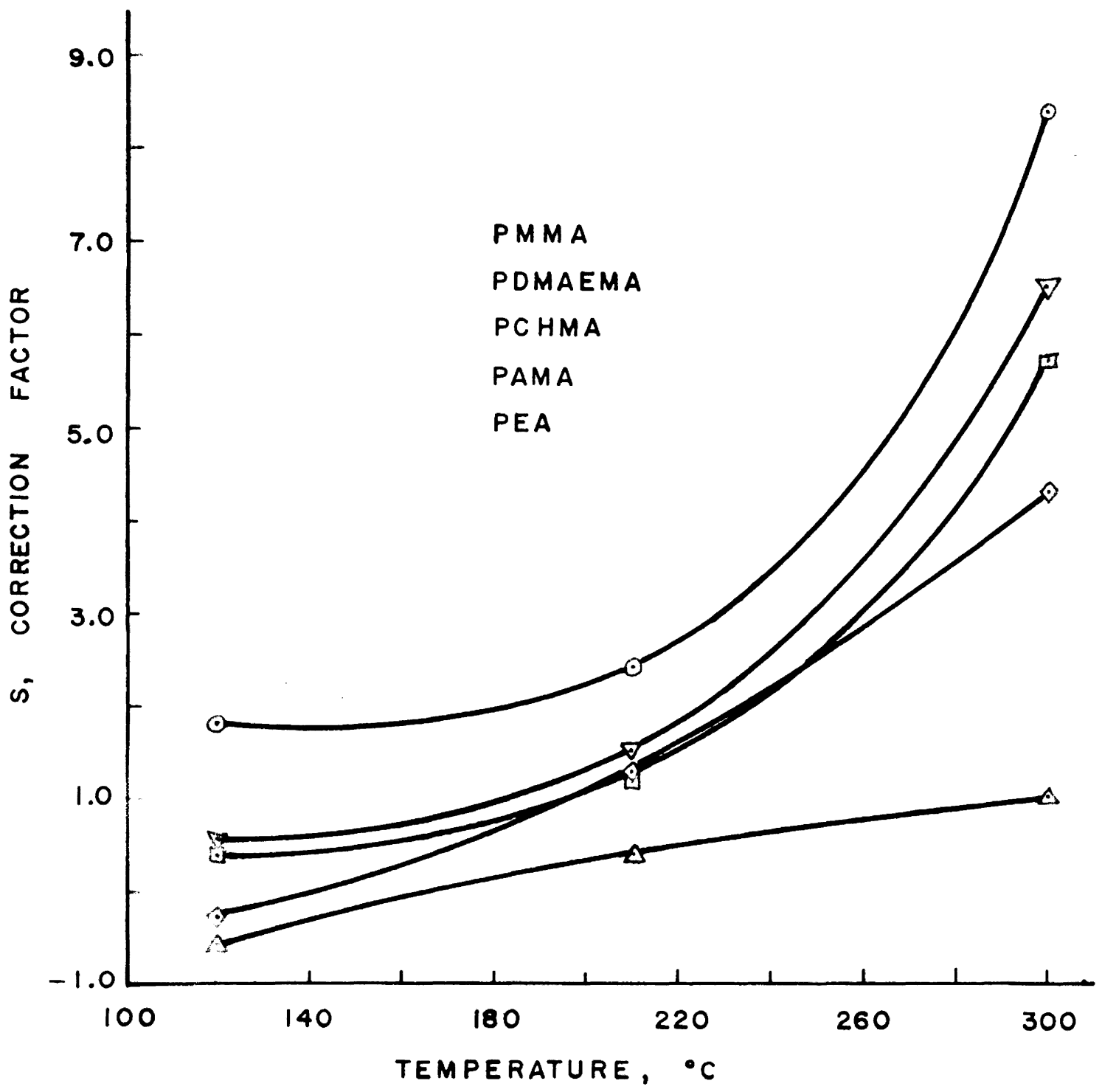

FIGURE 8. HEAT CAPACITY CORRECTION FACTORS AS FUNCTIONS OF TEMPERATURE 


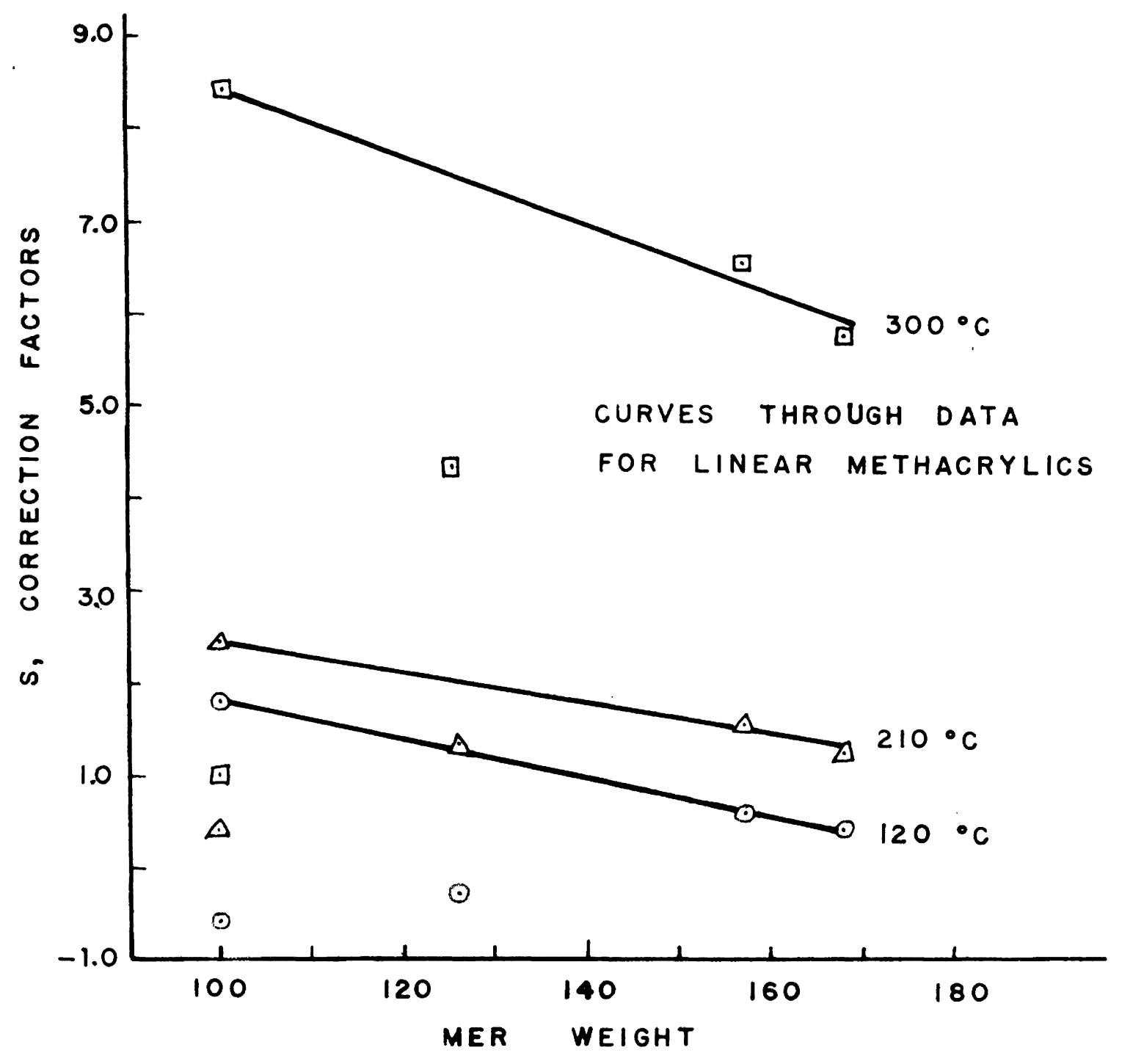

FIGURE 9. HEAT CAPACITY CORRECTION FACTOR AS A FUNCTION OF MER WEIGHT 
TABLE X.

Sakiadis and Coates' Specific Heat Estimations

Temperature Method Polymer d

${ }^{\circ} \mathrm{C}$ PMMA PDMAEMA PCHMA PAMA PEA

120

$\begin{array}{llllll}\text { a } & 0.66 & 0.40 & 0.31 & 0.19 & 0.17\end{array}$

$\begin{array}{llllll}\text { b } & 0.44 & 0.48 & 0.45 & 0.37 & 0.44\end{array}$

$\begin{array}{llllll}\text { C } & 0.66 & 0.41 & 0.31 & 0.56 & 0.67\end{array}$

210

$\begin{array}{llllll}\text { a } & 0.89 & 0.72 & 0.59 & 0.56 & 0.41 \\ \text { b } & 0.48 & 0.54 & 0.52 & 0.51 & 0.48 \\ \text { c } & 0.89 & 0.70 & 0.62 & 0.83 & 0.90\end{array}$

300

$\begin{array}{llllll}\text { a } & 2.52 & 2.36 & 2.21 & 1.58 & 0.63 \\ \text { b } & 0.50 & 0.58 & 0.57 & 0.55 & 0.54 \\ \text { c } & 2.52 & 2.29 & 2.30 & 1.75 & 2.92\end{array}$

a observed experimentally

b Estimated by Sakiadis and Coates (18) method

C Estimated by Sakiadis and Coates' method with modified correction factors

d Units are cal $/ \mathrm{gm}-{ }^{\circ} \mathrm{C}$. 


\section{Sample Calculations}

Sample calculations for enthalpy, enthalpy corrections, specific heats by numerical differentiation, and specific heat estimation by the method of Sakiadis and coates are included in this section.

Sample Enthalpies. Using the equation for enthalpy change stated by Smith and Van Ness(20), an energy balance was made about the calorimeter and solved for the sample enthalpy change. 


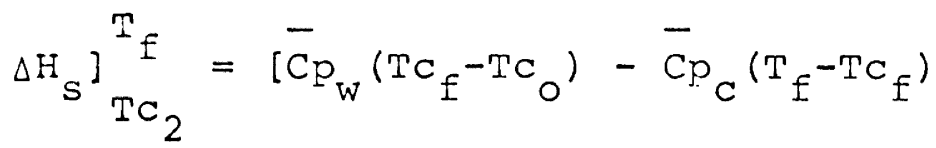

$$
\begin{aligned}
& \left.-h_{C} \Delta t\left(T_{r}-\bar{T}_{C}\right)\right] / m_{S}
\end{aligned}
$$

where:

$$
\begin{aligned}
& \Delta \mathrm{H}_{\mathrm{S}}{ }_{\mathrm{TC}_{2}}^{\mathrm{T}_{\mathrm{f}}}=\text { enthalpy changes of sample between furnace } \\
& \text { temperature and final calorimeter temperature, } \\
& \mathrm{cal} / \mathrm{gm} \\
& \overline{\mathrm{C}} \mathrm{p}_{\mathrm{W}}=\text { mean specific heat of one liter of water between } \\
& \text { initial and final calorimeter temperatures, } \\
& \operatorname{cal} /{ }^{\circ} \mathrm{C} \\
& \bar{C} p_{c}=\text { mean effective specific heat of capsule between } \\
& \text { furnace temperature and final calorimeter } \\
& \text { temperature, } \operatorname{cal} /{ }^{\circ} \mathrm{C} \\
& h_{C}=\text { heat transfer coefficient for calorimeter to } \\
& \text { room, } \mathrm{cal} / \mathrm{min}-{ }^{\circ} \mathrm{C} \\
& \Delta t=\text { time elapsed between measurement of initial and } \\
& \text { final calorimeter temperatures, min } \\
& \text { Tc } c^{\prime}, \mathrm{TC}_{f}=\text { initial and final calorimeter temperatures, }{ }^{\circ} \mathrm{C} \\
& \mathrm{T}_{\mathrm{f}}=\text { furnace temperature, }{ }^{\circ} \mathrm{C} \\
& \mathrm{T}_{\mathrm{r}}=\text { room temperature, }{ }^{\circ} \mathrm{C} \\
& \overline{\mathrm{T}}_{\mathrm{C}}=\text { average calorimeter temperature during arop } \\
& \text { time, }{ }^{\circ} \mathrm{C} \\
& m_{s}=\text { mass of sample, gm. }
\end{aligned}
$$


Substituting data from test 1, Table III, page 28, and from Table II, page 27 ,

$$
\begin{aligned}
\left.\Delta \mathrm{H}_{\mathrm{S}}\right]_{15.98}{ }_{120.5} & {[1000(17.17-16.14)-2.74(121.1-17.17)} \\
& -57.75(22.0-16.65)] / 5.5316 \\
= & 79.8 \mathrm{cal} / \mathrm{gm} .
\end{aligned}
$$

Enthalpy Corrections. In order to correct enthalpies to a common base of $15^{\circ} \mathrm{C}$ and to the nearest $10^{\circ} \mathrm{C}$ of the furnace temperature, a linear variation of enthalpy with temperature was assumed.

$$
\left.\underset{\left.H S_{C}\right]{ }_{15}{ }^{{ }^{\circ} \mathrm{C}}}{ }=\Delta \mathrm{H}\right]{ }_{\mathrm{TC}_{f}}^{\mathrm{T}_{f}}+\frac{\left.{ }_{\mathrm{H}}\right] \mathrm{TC}_{f}}{\left(\mathrm{~T}_{f}-\mathrm{TC}_{f}\right)}\left[\left(\mathrm{Tf}_{\mathrm{C}}-15^{\circ} \mathrm{C}\right)-\left(\mathrm{T}_{f}-\mathrm{TC}_{f}\right)\right]
$$

where:

$$
\begin{aligned}
& \left.\Delta \mathrm{Hs}_{\mathrm{C}}\right]_{15^{\circ} \mathrm{C}}^{\mathrm{Tf}}=\text { sample enthalpy corrected to } 15^{\circ} \mathrm{C} \text { and } \\
& \text { rounded upper temperature, cal/gm } \\
& T f_{C}=\text { furnace temperature rounded to nearest } \\
& 10^{\circ} \mathrm{C},{ }^{\circ} \mathrm{C} \text {. }
\end{aligned}
$$

All other terms are defined in the preceding section. Substituting for test 1 , Table III, page 28 ,

$$
\begin{aligned}
\Delta \mathrm{Hs}_{\mathrm{C}}{ }_{15}^{120^{\circ} \mathrm{C}} & =79.8+\frac{79.8[(120.0-15.0)-(121.1-17.17)]}{(121.1-17.17)} \\
& =80.6 \mathrm{cal} / \mathrm{gm} .
\end{aligned}
$$

Specific Heats. Milne ${ }^{(14)}$ suggests the following method of numerical differentiation for seven equally spaced data points. Neglecting the remainders for the equations, 


$$
\begin{aligned}
& y_{0}^{\prime}=\left(-147 y_{0}+360 y_{1}-450 y_{2}+400 y_{3}-225 y_{4}+72 y_{5}-10 y_{6}\right) / 60 \mathrm{~h} \\
& y_{1}^{\prime}=\left(-10 y_{0}-77 y_{1}+150 y_{2}-100 y_{3}+50 y_{4}-15 y_{5}+2 y_{6}\right) / 60 \mathrm{~h} \\
& y_{2}^{\prime}=\left(2 y_{0}-24 y_{1}-35 y_{2}+80 y_{3}-30 y_{4}+8 y_{5}-y_{6}\right) / 60 \mathrm{~h} \\
& y_{3}^{\prime}=\left(-y_{0}+9 y_{1}-45 y_{2}+45 y_{4}-9 y_{5}+y_{6}\right) / 60 \mathrm{~h} \\
& y_{4}^{\prime}=\left(y_{0}-8 y_{1}+30 y_{2}-80 y_{3}+35 y_{4}+24 y_{5}-2 y_{6}\right) 60 \mathrm{~h} \\
& y_{5}^{\prime}=\left(-2 y_{0}+15 y_{1}-50 y_{2}+100 y_{3}-150 y_{4}+77 y_{5}+10 y_{6}\right) / 60 \mathrm{~h} \\
& y_{6}^{\prime}=\left(10 y_{0}-72 y_{1}+225 y_{2}-400 y_{3}+450 y_{4}-360 y_{5}+147 y_{6}\right) / 60 \mathrm{~h}
\end{aligned}
$$

where:

$$
\begin{aligned}
& \mathrm{y}=\text { enthalpy at a temperature, cal } / \mathrm{gm} \\
& \mathrm{h}=\text { ordinate interval }=30^{\circ} \mathrm{C} .
\end{aligned}
$$

The subscripts zero to six correspond to $120^{\circ}$ to $300^{\circ} \mathrm{C}$ at 30 degree intervals, and the primed quantities represent specific heats at the subscripted temperature. Substituting data for PMMA from Table IV, page 30 ,

$$
\begin{aligned}
y_{4}^{\prime}= & {[74-8(100)+30(123)-80(149)+35(180)} \\
& +24(220)-2(282] / 60(30) \\
= & 1.09 \mathrm{cal} / \mathrm{gm}-{ }^{\circ} \mathrm{C} \text { at } 240^{\circ} \mathrm{C} .
\end{aligned}
$$

Sakiadis and Coates' Method. The equation developed by Sakiadis and Coates ${ }^{(18)}$ for estimating specific heats of organic liquids is shown on page 12. If one examines the mer structure of polymethyl methacrylate, one finds that $\mathrm{a}=6, \mathrm{n}=15$, and $\mathrm{s}=0.72$. Data from the aforementioned article was used to obtain the following table. 


\begin{tabular}{|c|c|c|c|c|c|c|c|c|c|c|}
\hline Bond & $q i_{v}$ & $q^{i} \delta$ & $w_{v}$ & $\mathrm{w}_{\delta}$ & $x_{v}$ & $\mathrm{x}_{\delta}$ & $C_{v}$ & $c_{\delta}$ & ${ }^{q_{i}} C_{v}$ & $g_{i} c_{\delta}$ \\
\hline $\mathrm{C}-\mathrm{H}$ & 8 & - & 2960 & - & 10.80 & - & 0.005 & - & 0.04 & - \\
\hline$c-0$ & 2 & 2 & 1030 & 205 & 3.77 & 0.75 & 0.680 & 1.90 & 1.36 & 3.80 \\
\hline$C-c$ & 4 & 4 & 900 & 370 & 3.29 & 1.35 & 0.860 & 1.70 & 3.44 & 6.80 \\
\hline $\mathrm{CH}_{3}$ & 6 & 6 & - & 1000 & - & 3.66 & - & 0.70 & - & 4.20 \\
\hline$C=0$ & 1 & 1 & 1700 & 390 & 6.21 & 1.43 & 0.160 & 1.69 & 0.16 & 1.69 \\
\hline $\mathrm{CH}_{2}$ & 2 & $\underline{2}$ & - & 1450 & - & 5.30 & - & 0.78 & - & 0.56 \\
\hline$\Sigma$ & 15 & 15 & & & & & & & 5.00 & 17.05 \\
\hline
\end{tabular}

If one assumes the use of the mer weight in place of molecular weight and that $\mathrm{C}_{\mathrm{p}} \approx \mathrm{C}_{\mathrm{v}}$ for a polymer, one obtains

$$
\begin{aligned}
C_{p} & =(6+6) 1.987+5.00+\frac{3(15)-6-6-15}{15}(0.72)(17.05) \\
& =43.54 \mathrm{cal} / \mathrm{gm} \mathrm{mole}-{ }^{\circ} \mathrm{K} \\
& =0.44 \mathrm{cal} / \mathrm{gm}-{ }^{\circ} \mathrm{C} .
\end{aligned}
$$


IV. DISCUSSION

In order to clarify the results of this study herein is included a discussion of the literature, procedures, and results, and a statement of the recommendations and limitations concerning the calorimeteric behavior of the polymers investigated.

\section{Discussion of Literature}

This section contains comments on the calorimeter used and the available estimation techniaues.

calorimeter. The calorimeter used by southard (23) was a much more sophisticated version of the one used in this experiment. Since the furnace assemblies were similar, the temperature distributions in them were assumed to be similar. The major differences were in the calorimeter sections themselves. Southard used a cylindrical copper block immersed in an oil bath maintained at $25.00 \pm 0.01 \mathrm{C}$, calibrated electrically. Considerable error was introduced by the use of a finned tube in a water bath as the calorimeter section.

One radiation shield was considered satisfactory in confiming heat losses up the tube in Southard's work. Two shields were used in the present experiments.

Specific Heat Estimations. There are several methods of predicting specific heat assuming additivity of atomic 
or atomic group heat capacities. Kopp's rule for solids (12

is applicable to crystalline structures. Gambrill(8) has applied Kopp's rule to liquids. Johnson and Huang (11) have added group contributions to predict specific heats of organic liquids. Chow and Bright (3) have developed an empirical approach for organics, using the parachor and molar refraction. All of these methods are for predictions at ordinary temperatures, and do not apply to polymeric materials.

Sakiadis and coates (18) have been highly successful with a semi-theoretical quantum mechanical estimation for organic liquids. A correction factor, s, was needed for the term involving the contribution to heat capacity from bond deformations. This factor is a function of molecular weight and type of compound.

\section{Passaglia's (17) linear continuum theory has been} successfully applied to polyethylene from $-25{ }^{\circ} \mathrm{C}$ to $55{ }^{\circ} \mathrm{C}$. It is based on a one-dimensional lattice model. As polymers soften at high temperatures, the specific heat is no longer proportional to the first power of the temperature; hence, the one dimensional model no longer applies.

There are no satisfactory theoretical methods for predicting high temperature heat capacities of polymer materials. 


\section{$\underline{\text { Discussion of Procedures }}$}

The experimental portion of this work concerned polymerization of the monomers and calorimetric determinations of the polymers.

Polymerizations. Bulk polymerizations in test tubes were found to yield clear, bubble-free samples. The polyallyl methacrylate, the polydimethylaminoethyl methacrylate and the polyethyl acrylate were light brown in color rather than clear, indicating the presence of impurities, probably inhibitor. The polyallyl methacrylate was more brittle than the others; the bifunctionality of the monomer structure was thought to have produced some crosslinking of the polymer chains.

Calorimetric Determinations. The nature of the calorimeter itself accounted for errors of several types. - ie calorimeter section consisted of a Dewar flask with the water surface open to the air. A temperature gradient of $1.3^{\circ} \mathrm{C}$ was observed with the use of the thermopile. The water in the calorimeter was 8 to $10^{\circ} \mathrm{C}$ lower than room temperature at the beginning of each test. The heat transfer to the room was accounted for by calculation of a heat transfer coefficient. Since the heat lost to the room was as high as 30 per cent of the heat absorbed by the water in the calorimeter for some tests, the accuracy of this 
coefficient was important.

The enthalpy calculation assumed that the calorimeter temperature was uniform at the final temperature value. An average temperature was found by positioning the thermopile such that true enthalpies of vitreous silica were obtained. The calibration was within five per cent of the values listed by Morey (15).

Partington (16) notes that one of the greatest sources of error in a water calorimeter is the evaporation of the water. Ten milligrams of water evaporated absorbs six calories, which normally introduces an error of 0.1 per cent. This source of error was neglected in this work because of the magnitude of the experimental error.

\section{Discussion of Results}

The data, specific heats, literature agreement, empirical correlation, application of present theories, and a modification of an organic liquid estimation method are discussed herein.

The Data. The sample enthalpies have a maximum deviation of ten per cent from the smoothed values. They are based on $15^{\circ} \mathrm{C}$, and there were no data to which they could be compared.

Figure 4, page 29, shows the similar behavior of the methacrylic polymers. The acrylic polymer's enthalpy 
temperature curve is flatter than those of the methacrylic polymers. However, the acrylic polymer had quite different physical properties, being soft and rubbery rather than hard. This family of curves for the methacrylates suggested a dependence of calorimetric behavior on polymer structure. Specific Heats. The specific heats of the polymers are listed in Table $V$, page 31 . Good agreement between the numerical differentiations and the measured slopes is found from $180^{\circ} \mathrm{C}$ to $270^{\circ} \mathrm{C}$. Values at high and low ends of the temperature range do not show such agreement. The curvature of the lines and the large increment used in the differentiation $\left(30^{\circ} \mathrm{C}\right)$ caused the discrepancies. The specific heats found by measured slopes are plotted in Figures 5 and 6 , pages 32 and 33 , because they seemed more reliable.

The specific heat behavior of the polymers shown in Figure 6, page 33, appear similar except for the polyallyl methacrylate. This polymer, however, is the only polyfunctional one studied. It is suspected that crosslinking occurred on polymerization. Therefore, it is quite possible that this polymer structure is very different from the other three mathacrylics, which are linear.

Iiterature Agreement. The agreement between Bernhardt's data $^{(1)}$ and the present work is shown in Figure 5 , page 32 . Although the mer weights of polymethyl methacrylate and 
polyethyl acrylate are the same, the difference in specific heat behavior reflects the differences in physical properties of the two polymers.

Empirical Correlation of Specific Heats. A common curve for the linear methacrylic polymers is shown in figure 7, page 35 . The mer weight was weighted by incorporating a power of inverse temperature. This suggests that the mer weight is less important at higher temperatures than at the lower ones. The softened polymer more closely resembles a liquid at higher temperatures and the molar heat capacities would be expected to be more similar than the solid state capacities. Data from the correlation are within twenty per cent of experimental values.

Application of Present Theories. Table VIII, page 37 , lists several methods of estimating specific heats. It has been noted earlier that Kopp's rule for solids (12) applies to crystalline materials. However, mobolsky (27) has shown that $x$-ray diffraction patterns for amorphous polymers are very similar to those of simple liauids. Therefore, one would expect the behavior of the amorphous polymers to be somewhere between crystalline solids and liquids. Thus, it is not surprising that values calculated from Kopp's rule for solids do not agree with experimental results.

Kopp's rule for liquids ${ }^{(8)}$ shows only slightly better 
agreement. It has been found to apply fairly well to liquids, but polymer structure is quite different from Iiquid structure. Iiquids are composed of relatively short molecules, while polymers consist of long molecular chains which may be entangled and intertwined. Johnson and Huang's(11) method, applicable for organic liquids, would also be expected to differ from polymer behavior for the same reasons. These calculations were made using the mer weight in place of the molecular weight of the liquid. Correct estimations would result if mer weights were factored by 1.43 for polymethyl methacrylate, 0.83 for polydimethylaminoethyl methacrylate, 0.74 for polycyclohexyl methacrylate, 0.44 for polyallyl methacrylate, and 0.40 for polyethyl acrylate at $120^{\circ} \mathrm{C}$. Since this method is for estimations at room temperature, the results do not agree with experimental values.

Modified Estimation Techniques. If one applies the method of sakiadis and coates (18), one obtains the results shown in Table $x$, page 41 , line $\underline{b}$. This method is a semi-empirical quantum mechanical approach utilizing a correction factor for the specific heat contribution due to bond deformations. Agreement with experimental results below $210^{\circ} \mathrm{C}$ is only fair. Here again the obvious structural differences between organic liquids and amorphous polymers account for the disagreement. 
Correction factors were calculated, (Table IX, page 38 ), and plotted against temperature in Figure 8 , page 39 . Sakiadis and Coates' factors for organic liquids depend only on molecular weight and type of compound. The factors for polymers are temperature dependent. This dependency shows similar behavior for the linear methacrylic polymers, which again suggests structural effects.

These correction factors were plotted against mer weight in Figure 9, page 40 . Constant temperature straight lines were drawn through the data for the linear methacrylic polymers. The acrylic polymer and polyfunctional polymer were disregarded because of the structural dissimilarity of the former and the unknown mer weight of the latter. The result indicates that this method could be a satisfactory correlation techniaue for linear polymers. The maximum deviation using the smoothed correction factors was six per cent; the resuits are shown in Table $x$, page 41 . The development of a theory for the prediction of polymer specific heats is a long and difficult job, beyond the scope of this work. A quantum mechanical approach seems to be the most promising at this time. It is suggested that available data be used in another thesis for the development of such a theory. 


\section{$\underline{\text { Recommendations }}$}

In order that greater accuracy be obtained, it is suggested that an electrically calibrated and well insulated metal cylinder be used in place of the present water bath calorimeter section.

It is recommended that structural properties (i.e., crystallinity, molecular weight distribution, etc.) be studied in relation to thermodynamic properties. These studies would aid in developing a general theory for polymer thermodynamics.

\section{Limitations}

Using a six-couple thermopile, operation below $100^{\circ} \mathrm{C}$ lowered accuracy because of small temperature changes in the calorimeter.

Temperatures in the furnace were measured accurately to $0.3^{\circ} \mathrm{C}$, while calorimeter temperatures were within $0.05^{\circ} \mathrm{C}$. The room temperature measurement was accurate to $0.1^{\circ} \mathrm{C}$. polymer degradation prevented measurements above $300^{\circ} \mathrm{C}$. 


\section{CONCLUSINNS}

The following conclusions concerning the calorimetric behavior of acrylic polymers were inferred:

1. Enthalpies and specific heats of polymethyl methacrylate, polydimethylaminoethyl methacrylate, polycyclohexyl methacrylate, polyallyl methacrylate, and polyethyl acrylate were obtained from 120 to $300^{\circ} \mathrm{C}$.

2. The linear methacrylic polymers showed calorimetric behavior that were correlated on a structural basis.

3. Available methods for estimating specific heats of solids were not applicable to the polymers studied.

4. Methods for amorphous materials (i.e., organic liquids) were found to be more successful provided a correction for mer weight was included.

5. The method of Sakiadis and Coates proved most successful for polymers with the use of modified correction factors based on mer weight and temperature. 


\section{SUMMARY}

The purpose of this work was to determine the enthalpies and specific heats of polymethyl methacrylate, polydimethylaminoethyl methacrylate, polycyclohexyl methacrylate, polyallyl methacrylate, and polyethyl acrylate from 120 to $300^{\circ} \mathrm{C}$, and to determine a method for estimating their specific heats.

Enthalpies of the selected polymers were determined by using a drop calorimeter constructed by the Chemical Engineering Department of Virginia Polytechnic Institute. Specific heats were obtained by measuring the slopes of the enthalpy-temperature curves.

Good agreement with existing data for polymethyl methacrylate was obtained. An existing semi-theoretical quantum mechanical method was modified to provide specific heat estimations for linear methacrylic polymers accurate within six per cent. An empirical correlation yielding estimations within twenty per cent was proposed. 


\section{BIBLIOGRAPHY}

1. Bernhardt, E.C.: "Processing of Thermoplastic Materials", p. 559. Reinhold Publishing Corporation, New York, N.Y., 1959.

2. Billmeyer, F. Ti.: "Textbook of polymer Science", D. 400. Interscience Publishers, Inc., New York, N.Y., 1962 .

3. Chow, W.M., and J.A. Bright, Jr., Chem. Eng. Prog., 49, 175 (1953).

4. Dainton, F.S., D.M. Evans, F.E. Hoare, and J.P. Melia

(Univ. Leeds, Engl.): Thermodynamic Functions of

Linear High Polymers. VIII. Methyl Methacrylate and Polymethyl Methacrylate, Polymer, 3 , 317-21 (1962).

5. Dole, M., N.R. Lawson, J.A. Wethington, Jr., and R.C. Wilhoit: Calorimetry of High Polymers. I. Automatic Temperature Recording and Control of Adiabatic Jackets, Rev. Sci. Instr., 22, 812-17 (1951).

6. Foster, G.N.: P-V-T Data for Polyolefins (Unpublished Ph.D. Thesis, Library, Va. Poly. Inst., Blacksburg, Va., i964).

7. Gambrill, W.R.: How to Estimate Engineering Properties, Chem Eng. 64, n6, 247 (1957).

8. ibia, n7, 268 (1957).

9. Ginnings, D.C. and R.J. Corruccini: Enthalpy, Specific Heat, and Entropy of Aluminum Oxide from 0 to $900^{\circ} \mathrm{C}$, J. Research Nati. Bur. Standards, 38, 593-600 (1947).

10. Haug, W.A.: The Physical and Thermodynamic Properties of Nylon 6-10, Unfinished M.S. Thesis (to be submitted in June 1965), Va. Poly. Inst., Blacksburg, Va.

11. Johnson, A.I. and C.J. Huang, Can. J. Technol., 33, 421 (1955).

12. Kopp, Annalen Der Chemie Erganzungsbande, 3 , $289(1864)$.

13. Levinson, L.S. (Los Alamos Sci. Lab., Los Alamos, N. Mex.), Rev. Sci. Instr., 33, 639-42 (1962). 
14. Milne, W.E.: "Numerical Calculus", p. 98. princeton University Press, Princeton, New Jersey, 1949.

15. Morey, G.W.: "The Properties of Glass", p. 215. Reinhold Publisining Corporation, New York, N.Y., 1938.

16. Partington, J.R.: "An Advanced Treatise on Physical Chemistry", vol. 3, p. 277. Longmans, Green and Company, London, England, 1952.

17. Passaglia, E. and H.K. Kevorkian: The Heat Capacity of Linear and Branched Polyethylene, J. Appl. Poly. Sci., 7, nl, 119-132 (1963).

18. Sakiadis, B.C., and J. Coates: Prediction of Specific Heat of Organic Liquids, A.I. Ch. E. Journal, $\underline{2}, 88-93$ (1956).

19. Smith, C.W., and M. Dole: Specific Heat of Synthetic High Polymers. VII. Polyethylene Terephthalate, J. Poly. Sci., 20, 37-56 (1956).

20. Smith, J.M. and H.C. Van Ness: "Introduction to Chemical Engineering Thermodynamics", p. 57. McGraw-Hill Book Company, Inc., New York, N.Y., 1959.

21. Sochava, I.V., Vestnik Leningrad Univ., Ser. Fiz. i Khim., 13,65 (1958).

22. and O.D. Trapeznikova: Vestnik Leningrad Univ., Ser. Fiz. i Khim., 13, 68 (1958).

23. Southard, J.C.: A Modified Calorimeter for High Temperatures, J. Am. Chem. Soc., 63, 3142 (1941).

24. Warfield, R.W. and M.C. Petree (U.S. Naval Ora. Lab., Silver Spring, Maryland): Thermodynamic Properties of Polymethyl Methacrylate and Methyl Methacrylate J. Poly. Sci., pt. Al, n5, 1701-8 (1963).

25. Worthington, A.F., P.C. Marx, and M. Dole: Calorimetry of High Poiymers. III. A New Type of Adiabatic Jacket and Calorimeter, Rev. Sci. Instr., 26, 698-702 (1955).

26. Wunderlich, B. and M. Dole: Specific Heat of Synthetic High Polymers. VIIT. Low Pressure Polyethylene, J. Poly. Sci., 24, 201 (1957). 
$\underline{\text { Addenda }}$

27. Tobolsky, A.V.: "Properties and Structure of Polymers", p. 43. John Wiley and Sons, Inc., New York, N.Y., (1960). 


\section{ACKNONLEDGFMFNTS}

The author wishes to express his appreciation to his advisor, Dr. R.G. Griskey, who suggested the topic and offered invaluable suggestions throughout the project.

Appreciation is expressed to Mr. N. Waldman for his advice concerning the experimental part of this study.

To Mrs. Richard W. Thompson, who spent many hours typing these pages, the author also expresses his thanks. 
The vita has been removed from the scanned document 


\section{AESTRACT}

The purpose of this work was to deternine the enthalpies and specific heats of polymethyl methacrylate, polydimethylaminoethyl methacrylate, polycyclohexyl methacrylate, polyallyl methacrylate, and polyethyl acrylate from 120 to $300^{\circ} \mathrm{C}$, and to determine a method for estimating their specific heats.

Enthalpies of the selected polymers were determined by using a drop calorimeter constructed by the Chemical Engineering Department of Virginia Polytechnic Institute. Specific heats were obtain d by measuring the slopes of the enthalpy-temperature curves.

Good agreement with existing data fo: polymethyl methacrylate was obtained. An existing semi-theoretical quantum mechanical method was modified to provide specific heat estimations for linear methacrylic polymers accurate within six per cent. fan empirical estimations within twenty per cent was proposed. 